\title{
Modelling of gasoline fuel droplets heating and evaporation
}

\author{
M. Al Qubeissi, S.S. Sazhin*, J. Turner, S. Begg, C. Crua, M.R. Heikal \\ Centre for Automotive Engineering, School of Computing Engineering and Mathematics, University of Brighton,
}

Brighton BN2 4GJ, United Kingdom

\begin{abstract}
The paper presents a new approach to modelling of the heating and evaporation of gasoline fuel droplets with a specific application to conditions representative of internal combustion engines. A number of the components of gasoline with identical chemical formulae and close thermodynamic and transport properties are replaced with characteristic components leading to reducing the original composition of gasoline fuel (83 components) to 20 components only. Furthermore, the approximation to the composition of gasoline with these components is replaced with a smaller number of hypothetical quasi-components/components as previously suggested in the multi-dimensional quasi-discrete (MDQD) model. The transient diffusion of quasi-components and single components in the liquid phase as well as the temperature gradient and recirculation inside the droplets, due to the relative velocities between the droplets and the ambient air, are accounted for in the model. In the original MDQD model, n-alkanes and iso-alkanes are considered as one group of alkanes. In this new approach, the contributions of these two groups are taken into account separately. The values for the initial model parameters were selected from experimental data measured in a research engine prior to combustion. The results are compared with the predictions of the single-component model in which the transport and thermodynamic properties of components are averaged, diffusion of species is ignored and liquid thermal conductivity is assumed to be infinitely large, or approximated by those of iso-octane. It is shown that the application of the latter models leads to an under-prediction of the droplet evaporation time by approximately 67\% (averaged) and 47\% (iso-octane), respectively, compared to those obtained using the discrete component model, taking into account the contributions of 20 components. It is shown that the approximation of the actual composition of gasoline fuel by 6 quasi-components/components, using the MDQD model, leads to an under-prediction of the estimated droplet surface temperatures and evaporation times by approximately $0.9 \%$ and $6.6 \%$ respectively, for the same engine conditions. The application of the latter model has resulted in an approximately 70\% reduction in CPU processor time compared to the model taking into account all 20 components of gasoline fuel.
\end{abstract}

Keywords: Droplet heating, evaporation, hydrocarbon fuel, gasoline fuel

*Corresponding author, e-mail: $\underline{\text { S.Sazhin@brighton.ac.uk, telephone: +44(0)1273 } 642677}$ 


\section{Introduction}

Gasoline is a fuel widely used in internal combustion engines [1-4]. It is a middle distillate of petroleum, mainly containing C4-C12 hydrocarbons [1,2]. Gasoline fuel droplet heating and evaporation are critical phases in the mixture preparation process that is central to optimum combustion engine efficiency. The accuracy in modelling of these processes has become increasingly important in improving and validating the performance of these combustion systems (e.g. stratified charge, direct injection etc.) $[3,5,6]$. There have been several approaches to accurate modelling of fuel droplet heating and evaporation [7-16]. In many studies, gasoline fuels are approximated with iso-octane (2,2,4-trimethylpentane structure) (see [17-19]); while realistic gasoline fuels include tens of numbers of hydrocarbons [20]. A typical example of a gasoline fuel composition used as Fuel for Advanced Combustion Engines (FACE C) is shown in Table 1 (see [2] for the details of other compositions of FACE gasoline fuels).

Two main approaches have been used for the analysis of fuel droplet heating and evaporation taking into account its multi-component composition. The first approach is based on the analysis of individual components, the Discrete Component (DC) model [21-28], that is generally applicable to the cases when relatively small numbers of components need to be taken into account. The second approach is based on the probabilistic analysis of a large number of components. This approach has been used in the continuous thermodynamics [29-36] and the distillation curve [37-39] models. In the second approach a number of additional simplifying assumptions have been used, including the assumption that species inside droplets either mix infinitely quickly (infinite diffusivity (ID) model) or do not mix at all (single-component (SC) model). In addition, the temperature gradients inside the droplets have been ignored in most cases by assuming that the liquid thermal conductivity is infinitely large (infinite thermal conductivity (ITC) model). These assumptions have been considered too approximate for the modelling of representative automotive fuel droplets, heating and evaporation $[3,8,11,12,40,41]$. As a compromise, several modelling approaches combining the benefits of the two aforementioned approaches, were suggested in $[35,42-44]$. Apart from these approaches a number of authors (e.g. $[45,46])$ focused their analyses on the numerical solution of the full Navier-Stokes equations for multi-component droplets. It is not feasible at the moment, however, to use such an approach for modelling realistic fuel sprays in internal combustion engines, taking into account all the complexities of the fluid dynamics, heat/mass transfer and combustion processes.

A new model for the heating and evaporation of multi-component fuel droplets, known as the multi-dimensional quasi-discrete (MDQD) model, was introduced in [13]. This model is based on further development of the ideas described in $[8,12]$, where the so called quasi-discrete model was suggested and tested. In the MDQD model a large number (up to about one hundred) of components have been replaced with a smaller number of quasi- 
components/components, taking into account the contributions of various groups of species (apart from alkanes) in representative Diesel fuel droplets. The quasi-components have been introduced as hypothetical species with non-integer numbers of carbon and hydrogen atoms (see [8,12] for further details). In our analysis here, the MDQD model has been applied to the analysis of gasoline fuel droplets. In contrast to [13,47], the contributions of the two groups of alkanes, n-alkanes (n-paraffin) and iso-alkanes (iso-paraffin), are considered separately, taking into account the differences in their thermodynamic and transport properties.

In the following section, the composition of FACE gasoline fuel used in our paper is described. The main features of the model used in our analysis are summarised in Section 3. The results of calculations are presented in Section 4, and the main results of the paper are summarised in Section 5.

\section{Composition of gasoline fuel}

Our analysis is focused on FACE-C gasoline fuel, the normalised composition of which is shown in Table 1 [1] where the unidentified components (with up to $0.087 \%$ of total molar fractions) are ignored. Data presented in this table are close to average contributions of species for several types of gasoline fuels [20].

Note that some components shown in Table 1 have similar carbon numbers, chemical formulae and thermodynamic and transport properties. The main differences between these components are their molecular structures, as illustrated for some molecules in Fig. 1. This allows us to replace these groups of similar components with single components (with averaged properties, based on averaged molar weights; or the ones with the highest molar contributions in the groups with molar fractions up to 1.5\%); see the penultimate column in Table 1 . This approach allows us to reduce the number of species in gasoline fuel to 20 components. These components are allocated to 3 groups, n-alkanes ( 5 components), iso-alkanes (8 components), and aromatics (4 components); and 3 components approximating groups with small molar fractions (indanes/naphthalenes, cycloalkanes and olefins). Molar fractions of these groups and components are shown in Table 2.

\section{Model}

Following $[11,13,16,40,48,49]$, the analyses are based on the assumption that droplets are spherically symmetric; the temperature gradient and species diffusions in the liquid phase and the effect of internal recirculation due to the relative velocity between the ambient gas and droplets are taken into account. The effects of coupling between gas and droplets are ignored (see [50] for a possible approach to take into account this effect).

The previously developed multi-dimensional quasi-discrete (MDQD) model, in which the actual composition of fuel is reduced to a much smaller number of representative quasi-components/components (QC/C), is used in our analysis. In this model, the effects of finite liquid thermal conductivity, QC/C diffusivity and recirculation are 
taken into account using the Effective Thermal Conductivity and Effective Diffusivity (ETC/ED) models. The analyses are based on the previously obtained analytical solutions to the heat transfer and species diffusion equations within droplets (see [6,10,51-53]). In contrast to [13,47], where the MDQD model was applied to 9 groups of components, our analysis is focused on 6 groups (shown in Table 2). Three of these groups are approximated by single components, while QC are generated for three remaining groups of alkanes: $\mathrm{n}$-alkanes (n-paraffins), iso-alkanes (i-paraffins) and aromatics. For each group $m$ ( $m=1$ to 3 ), the values of carbon numbers $\bar{n}_{j m}$ for QC can be introduced, following [13], as:

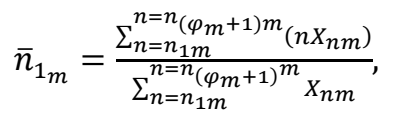

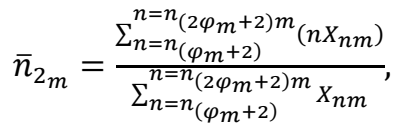

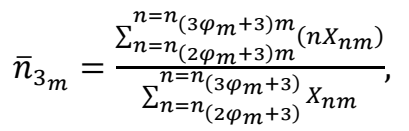

(2)

:

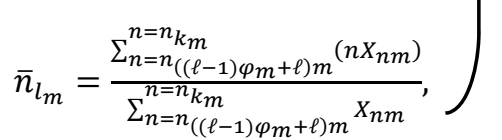

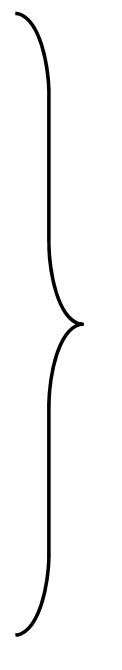

where $X_{n m}$ are molar fractions of components with carbon number $n$ within the group $m, n_{1 m}=n_{m(\min )}$ is the minimal value of $n$ in group $m, n_{k m}=n_{m(\max )}$ is the maximal value of $n$ in group $m, \ell=\operatorname{integer}\left(\left(k_{m}+\varphi_{m}\right) /\right.$ $\left.\left(\varphi_{m}+1\right)\right), \varphi_{m}+1$ is equal to the number of components to be included within each quasi-component. $k_{m}$ is the number of components within each group $m, \varphi_{m}$ is assumed to be the same for all QC within group $m$. If $\varphi_{m}=0$ then $\ell=k_{m}$ and the number of $\mathrm{QC}$ is equal to the number of actual components.

The number of components contributing within each QC $\left(n_{c m}\right)$, except possibly the last one, could be taken equal to the nearest integer of the ratio $n_{k m} / n_{q m}$, where $n_{q m}$ is the number of quasi-components in each group $m$. As in the case of the original MDQD model, $\bar{n}_{i m}$ are not integers in the general case. Note that the above approach cannot be applied in the case when $n_{q m}$ are close to the numbers of components in each group. In this case, some components within groups form quasi-components, while other components are considered separately. In this case a mixture of quasi-components/components (QC/C) is formed in such a way that the molar fractions of these QC/C are as close as possible. This approach is used in our analysis.

As in [13], the molar fractions of quasi-components are estimated as:

$$
X_{1_{m}}=\sum_{n=n_{1 m}}^{n=n_{\left(\varphi_{m}+1\right) m}} X_{n m}
$$




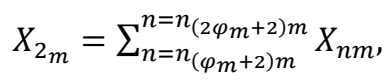

$$
X_{l_{m}}=\sum_{n=n_{\left((\ell-1) \varphi_{m}+\ell\right) m}^{n=n_{k m}}}^{n} X_{n m}
$$

As in $[13,47]$, the mixtures are treated as ideal (Raoult's law is assumed to be valid [54]). In this case, partial pressures of individual quasi-components/components $(\mathrm{QC} / \mathrm{C})$ are estimated as:

$p_{v}\left(\bar{n}_{i m}\right)=X_{l s i m}\left(\bar{n}_{i m}\right) p^{s a t}\left(\bar{n}_{i m}\right)$,

where $X_{\text {lsim }}$ are the molar fractions of liquid QC/C at the surface of the droplet, $p^{\text {sat }}\left(\bar{n}_{i m}\right)$ are calculated from the data presented in Appendices A-D. As assumed in our previous studies (e.g. [8,12,13,55]), gasoline fuel vapour diffuses from the surface of the droplet, without changing its composition, based on averaged binary diffusion of fuel into dry air. The gasoline fuel vapour is replaced with the vapour of iso-octane; the binary diffusion coefficient is estimated using the following expression [56]:

$D_{v a}=\left(A+B T+C T^{2}\right) \times 10^{-4}\left(\mathrm{~m}^{2} \mathrm{~s}^{-1}\right)$,

The results of calculations, using the above-described model, will be compared with the predictions of simplified models based on the assumptions that liquid thermal conductivity is infinitely high (Infinite Thermal Conductivity (ITC) model) and liquid species diffusivity is infinitely fast (Infinite Diffusivity (ID) model) or infinitely slow (Single Component (SI) model).

\section{Results}

The initial modelling parameters were determined from a set of experimental data of fuel droplets and gas velocity measured in an optically accessed, direct injection research engine, at part and full load, engine-like conditions at an engine speed of $1000 \mathrm{rpm}$. The axial velocity component of the fuel droplets and gas seeding particles (up to the instance of fuel injection) in the axial direction of the cylinder, at locations along the axis of the fuel injector, were recorded with respect to time using the Phase and Laser Doppler Anemometry techniques. The fuel droplet size distributions were measured from the start of fuel injection. The results applicable to the model were selected for a part load engine case, whereby fuel injection occurred during the late stages of the compression stroke. The fuel droplet data was ensemble-averaged within the first crank angle interval, immediately following the start of fuel injection, that contained at least 50 measurement records. The mean diameter of droplets at the initial stage of evaporation is taken equal to $24 \mu \mathrm{m}$, their axial velocity component and initial temperatures are assumed equal to $U_{\mathrm{drop}}=20 \mathrm{~m} / \mathrm{s}$ and $T_{d}=296 \mathrm{~K}$, respectively, air axial velocity component (at the instance prior to fuel injection) is assumed equal to $U_{\text {air }}=-4 \mathrm{~m} / \mathrm{s}$ (leading to a relative droplet axial velocity component of 24 $\mathrm{m} / \mathrm{s}$ ), ambient air (gas) pressure and temperature are assumed equal to $p_{g}=9$ bar and $T_{g}=545 \mathrm{~K}$, respectively. 

are shown: (1) the contributions of all 20 components are taken into account using the ETC/ED model (indicated as (ME)); (2) the contributions of 20 components are taken into account using the ITC/ID model (indicated as (MI)); (3) the thermodynamic and transport properties of 20 components are averaged to form a single component and temperature gradient is ignored (ITC model) (indicated as (SI)); and (4) the ITC model in which gasoline fuel is approximated with iso-octane (2,2,4-trimethylpentane; indicated as (IO)) is used.

As one can see from Fig. 2, the errors in droplet surface temperatures and evaporation times, predicted by the SI model are $13.6 \%$ and $67.5 \%$, respectively. For the IO model these errors reduce to $6.3 \%$ and $47.1 \%$, respectively, and reduce further to $4.8 \%$ and $8 \%$, respectively, when the MI model was used. Although the accuracy of the latter model might be acceptable in some engineering applications, this model cannot describe adequately the underlying physics of the processes inside droplets (heat conduction and species diffusion) as demonstrated later in this section. Note that the approximation of iso-alkanes with n-alkanes, as implemented in the previously developed slight increase in the evaporation time (by $0.1 \%$ ).

The same plots as in Fig. 2 but for the cases when 20 components of gasoline fuel are approximated by 15, 11 and 7 QC/C (see Table 3) , using the ETC/ED model are shown in Fig. 3. As can be seen in this figure, the errors in surface temperatures and evaporation times predicted by the model using $15 \mathrm{QC} / \mathrm{C}$ are $0.3 \%$ and $1.3 \%$, respectively. These errors increase to $0.5 \%$ and $4 \%$, respectively, when gasoline fuel is approximated by $11 \mathrm{QC} / \mathrm{C}$, and further increase to $0.8 \%$ and $6.4 \%$, respectively, when gasoline fuel is approximated by 7 QC/C. Even in the latter case, however, these errors can be tolerated in some practical engineering applications. The accuracy of this model is better compared with the accuracy of the MI model, and it describes adequately the underlying physics of the processes in droplets.

The same plots as in Fig. 3 but for the cases when 20 components of gasoline fuel are approximated by 6, 54 and $3 \mathrm{QC} / \mathrm{C}$ (see Table 3), using the ETC/ED model are shown in Figs. 4 and 5. As can be seen in these figures, the errors in surface temperatures and evaporation times predicted by the model using $6 \mathrm{QC} / \mathrm{C}$ are $0.8 \%$ and $6.6 \%$, respectively. These errors increase to $2.3 \%$ and $9.3 \%$, respectively, when gasoline fuel is approximated by 5 QC/C, and further increase to $2.3 \%$ and $9.7 \%$, respectively, when gasoline fuel is approximated by 4 QC/C, and to $2.4 \%$ and $15.8 \%$, respectively, when gasoline fuel is approximated by $3 \mathrm{QC} / \mathrm{C}$. In the latter 3 cases, these errors are larger than those for the MI model and cannot be tolerated in most engineering applications.

The mass fractions of several components, selected out of 20 components, at the surface of the droplet versus time for the same conditions as in Figs. 2-5, are shown in Fig. 6. As can be seen from this figure, the surface mass 
150

151

152

153

154

155

156

157

158

159

160

161

162

163

164

165

166

167

168

fraction of the heaviest component, $\mathrm{C}_{12} \mathrm{H}_{26}$, increases with time at the expense of the surface mass fractions of the light components, $\mathrm{C}_{5} \mathrm{H}_{12}$ and $\mathrm{C}_{7} \mathrm{H}_{16}$, which decrease with time; the mass fractions of intermediate components first increase and then decrease with time. This behaviour is similar to the one observed for the components in Diesel fuel droplets [13].

Mass fractions of n-pentane $\mathrm{C}_{5} \mathrm{H}_{12}$ and propylbenzene $\mathrm{C}_{9} \mathrm{H}_{12}$ versus normalised distance from the centre of $\operatorname{droplet}\left(R / R_{d}\right)$ at four time instants, $0.02 \mathrm{~ms}, 0.3 \mathrm{~ms}, 0.5 \mathrm{~ms}$ and $1 \mathrm{~ms}$ are shown in Fig. 7. As can be seen from this figure, the decrease of mass fraction of n-pentane with time at the surface of the droplet leads to the generation of n-pentane mass fraction gradient in the body of the droplet. This, in its turn, leads to n-pentane diffusion from the centre of the droplet to its surface. Similarly, the increase of mass fraction of propylbenzene with time at the surface of the droplets leads to the generation of propylbenzene negative mass fraction gradient in the body of the droplet and to propylbenzene diffusion from the surface of the droplet to its centre.

The plots of temperatures versus normalised distance from the centre of the droplet at four time instants are shown in Fig. 8. As one can see from this figure, the effect of temperature gradient due to finite thermal conductivity inside the droplet cannot be ignored, especially at the initial stage of evaporation. This questions the applicability of the widely used Infinite Thermal Conductivity (ITC) model of droplet heating and evaporation.

The predicted values of droplet radii $\left(R_{d}\right)$ versus the number of QC/C at four time instants are shown in Fig. 9. As can been seen from this figure, the predictions of the model based on the approximation of gasoline fuel by 6 or more QC/C give reasonably good agreements with the predictions of the model taking into account all 20 components of gasoline fuel.

Note that when the approximation to the 20-components by a smaller number of QC/C is applied, the greater deviation in evaporation time is predominantly due to the very last evaporation period (see Figures 3 and 4) i.e. when droplets have reached sizes of the order of 1-2 $\mu \mathrm{m}$, while differences are much smaller for droplets of a larger size. Considering that the residual mass of $1-2 \mu \mathrm{m}$ drops is insignificant when compared to the total evaporated mass, this observation may further increase the reliability of the chosen approximations.

The plots similar to those shown in Fig. 9, but for droplet surface temperatures, are presented in Fig. 10. As in the case shown in Fig. 9, we can see from Fig. 10 that the approximations of gasoline fuel by 6 or more QC/C give reasonably good agreements with the predictions of the model taking into account the contributions of all 20 components of gasoline fuel. These results are compatible with those inferred from the analysis of Figs. 3-5.

The CPU efficiencies of the model versus the numbers of QC/C are shown in Fig. 11 (the PC used is an Intel Xeon (core duo) E8400, $3 \mathrm{GHz}$ and $3 \mathrm{~GB}$ RAM). As can be seen from this figure, approximating 20 components of 
180

181

182

183

184

185

186

187

188

189

190

191

192

193

194

195

196

197

198

199

200

201

gasoline fuel by $6 \mathrm{QC} / \mathrm{C}$ reduces the required $\mathrm{CPU}$ time by more than $70 \%$ compared with the model taking into account the contributions of all 20 components. As can be inferred from the above analysis, choice of $6 \mathrm{QC} / \mathrm{C}$ can ensure a good compromise between CPU efficiency of the model and its accuracy.

\section{Conclusions}

A new approach to modelling of the heating and evaporation of gasoline fuel droplets in representative conditions for a direct injection internal combustion engine is described. The components with similar molecular formulae but different molecular structures are replaced with single components, leading to the reduction of the total number of components used in modelling to 20 . As in the previously suggested multi-dimensional quasi-discrete (MDQD) model, these 20 components of the fuel are replaced with a smaller number of hypothetical quasi-components and components. Transient diffusion of these quasi-components/components in the liquid phase, temperature gradient and recirculation inside droplets due to relative velocities between droplets and ambient air are taken into account.

In contrast to the original MDQD model, where n-alkanes and iso-alkanes are merged into one group of alkanes, this approach separates the contributions of these two groups. The results are compared with the predictions of several simplified models. In these models, the contributions of 20 components are taken into account using the infinite thermal conductivity/infinite species diffusivity (ITC/ID) model; the thermodynamic and transport properties of 20 components are averaged to form a single component and temperature gradient is ignored (ITC model); and the ITC model in which gasoline fuel is approximated with iso-octane (2,2,4-trimethylpentane). It is shown that the application of the latter two simplified models leads to under-prediction of the droplet evaporation time by up to $67 \%$ and $47 \%$, respectively, compared to the ones obtained using the discrete component model taking into account the contributions of 20 components. . The ITC/ID model leads to under-prediction of this evaporation time by $8 \%$, which can be acceptable in some engineering applications. This model, however, cannot describe adequately the underlying physics of the processes inside droplets (heat conduction and species diffusion).

It is shown that the approximation of the actual composition of gasoline fuel by 6 quasi-components/components, using the MDQD model, leads to errors in estimated droplet surface temperatures and evaporation times of about $0.9 \%$ and $6.6 \%$ respectively, for the same engine conditions, which can be tolerated in many practical engineering applications. It is shown that the application of the latter model leads to about $70 \%$ reduction in CPU time compared to the model taking into account the contributions of all 20 components of gasoline fuel. 


\section{Acknowledgements}

210 The authors are grateful to Ahmed Elwardany and Paul Harris for useful discussions, and INTERREG IVa (Pro-

211 ject E3C3 (4274), Project CEREEV (4224)) and EPSRC (project EP/K020528/1) and the University of Brighton for

212 their financial support to the project. 


\section{Appendices}

214 A. Transport and thermodynamic properties of n-alkanes

215 A.1. Molecular structure, boiling and critical temperatures

216 The chemical formula for $n$-alkanes is $\mathrm{C}_{\mathrm{n}} \mathrm{H}_{2 \mathrm{n}+2}$. Using data from [56-58] the dependences of boiling temperature at 217 atmospheric pressure, critical temperature and pressures on $n$ were approximated by the following equations, 218 valid for the range $4 \leq n \leq 12$ :

$T_{b}=-1.1328 n^{2}+45.02 n+111.68 \quad(\mathrm{~K})$,

$T_{c r}=-1.7679 n^{2}+56.967 n+227.57 \quad(K)$

$P_{c r}=-0.0404 n^{3}+1.2475 n^{2}-14.239 n+79.185$ (bar).

222 Regressions in Eqs. (5)-(7) were shown to lead to errors of up to $0.4 \%, 0.5 \%$ and $1.3 \%$ respectively.

223

\section{A.2. Liquid density}

Liquid density was approximated as $[56,57]$ :

$\rho(T)=1000 A B^{-\left(1-T_{r}\right)^{C}}\left(\mathrm{~kg} \mathrm{~m}^{-3}\right)$,

where coefficients $A, B$ and $C$, as functions of the carbon number $n$, were approximated as (leading to maximum errors of $0.24 \%, 0.22 \%$ and $2.2 \%$ respectively):

$A=-0.000248142613151153 n^{2}+0.00470185738684884 n+0.213705550811272$,

$B=0.0000384180187873567 n 2-0.00298658198121256 n+0.282644927412468$, and

$C=0.0000635183603757482 n^{2}-0.000196481639624268 n+0.279692698548249$.

\section{A.3. Liquid viscosity}

Liquid viscosity was approximated as [56,57].:

$\mu=10^{\left(a+\frac{b}{T}+c T+d T^{2}\right)-3}\left(\mathrm{~Pa}^{-1}\right)$,

where the values of coefficients are presented in Table 4.

\section{A.4. Liquid heat capacity}

The temperature dependence of heat capacity, applicable to all groups, is approximated as [59-61]:

$c_{p}=\mathrm{A}_{1}+\mathrm{A}_{2} T+\mathrm{A}_{3} T^{2} \quad\left(\mathrm{~J} \cdot \mathrm{kg}^{-1} \mathrm{~K}^{-1}\right)$,

where

$A_{1}=4184\left(-1.17126+(0.023722+0.024907 \tilde{\rho}) K_{\mathrm{W}}+\frac{1.14982-0.046535 K_{\mathrm{W}}}{\widetilde{\rho}}\right)$,

$A_{2}=7531.2\left(\left(10^{-4}\right)\left(1+0.82463 K_{\mathrm{W}}\right)+\left(1.12172-\frac{0.27634}{\widetilde{\rho}}\right)\right)$ 
$A_{3}=13556.16\left(\left(-10^{-8}\right)\left(1.0+0.82463 K_{\mathrm{W}}\right)+\left(2.9027-\frac{0.70958}{\widetilde{\rho}}\right)\right)$,

$T_{r}=T / T_{c r}$ is the reduced temperature, $T$ is the temperature (in $\mathrm{K}$ ), $T_{c r}$ is the critical temperature (in $\mathrm{K}$ ), $K_{\mathrm{W}}$ is the Watson characterisation factor, calculated as $K_{\mathrm{W}}=\left(1.8 T_{b}\right)^{\frac{1}{3}} / \tilde{\rho}$ (see [62]), and $\tilde{\rho}$ is the relative density at 288.706 $\mathrm{K}$, as shown in Table 5. Approximation (10) is valid for $0.4<T_{r}<0.85$.

\section{A.5. Liquid thermal conductivity}

Following $[1,58,63]$, the liquid thermal conductivity of $n$-alkanes was estimated, using the Latini formula, as:

$\lambda_{L}=\frac{A\left(1-T_{r}\right)^{0.38}}{\left(T_{r}\right)^{\frac{1}{6}}} \quad\left(\mathrm{~W} \mathrm{~m} m^{-1} \mathrm{~K}^{-1}\right)$

where $\lambda_{L}$ is thermal conductivity of liquid, $A$ is given in the following expression [64]:

$A=\frac{A * T_{b}{ }^{\alpha}}{M_{w}{ }^{\beta} T c^{\gamma}}$,

$M_{w}$ is molar mass (in $\mathrm{g} \mathrm{mol}^{-1}$ ); the values of other coefficients are shown in Table 6.

\section{A.6. Saturated vapour pressure}

Following [58,65], saturated vapour pressure of $n$-alkanes (in Pa) was calculated from the following equation:

$\ln P_{r}^{\text {vap }}=f^{0}\left(T_{r}\right)+\omega f^{1}\left(T_{r}\right)$,

254 where $f^{0}$ and $f^{1}$ are the Pitzer's functions of $T_{r}$ :

$f^{0}\left(T_{r}\right)=5.92714-\frac{6.09648}{T_{r}}-1.28862 \ln T_{r}+0.169347 \ln T_{r}{ }^{6}$,

$f^{1}\left(T_{r}\right)=15.2518-\frac{15.6875}{T_{r}}-13.4721 \ln T_{r}+0.43577 \ln T_{r}{ }^{6}$,

$\omega=\frac{-\ln P_{c r}-f^{0}(\theta)}{f^{1}(\theta)}$ and $\theta=\frac{T_{b}}{T_{c r}}$.

Eq. (13) is applied to all other groups of components in gasoline fuels.

\section{A.7. Enthalpy of evaporation}

Enthalpy of evaporation was estimated using the following expression [56]:

$L=A\left(1-T_{r}\right)^{B} \times 10^{6} / M w\left(\mathrm{~kg}^{-1}\right)$,

where coefficients $A$ and $B$ are given in Table 7 .

\section{B. Transport and thermodynamic properties of iso-alkanes}

\section{B.1. Molecular structure, boiling and critical temperatures}

Using data from [56] the dependence of the boiling temperature at atmospheric pressure, critical temperature and pressure were approximated by the following expressions, valid for the range $4 \leq n \leq 11$ :

$T_{b}=-1.1597 n^{2}+44.011 n+107.75 \quad(\mathrm{~K})$ 
$T_{c r}=-2.4511 n^{2}+66.891 n+183.88(\mathrm{~K})$,

$P_{c r}=-0.0186 n^{3}+0.459 n^{2}-5.924 n+54.071$ (bar).

Errors of Approximations (17)-(19) were estimated to be $1.45 \%, 1.61 \%$ and $1.17 \%$, respectively.

271

272 273

\section{B.2. Liquid density}

The temperature dependence of the liquid density of iso-alkanes was approximated by Expression (8) with coefficients $A, B$ and $C$ estimated as [56]:

$A=-0.000981411583995317 n^{2}+0.0167403553403262 n+0.175683060992056$,

$B=-0.000706081955526297 n^{2}+0.00873629109926122 n+0.249117016533684$, and

$C=0.00114456989247312 n^{2}-0.0174424731182795 n+0.343958172043011$.

\section{B.3. Liquid viscosity}

The liquid viscosity of iso-alkanes was estimated based on Expression (9) with coefficients given in Table 8 [56,57].

\section{B.4. Liquid heat capacity and thermal conductivity}

Following [59-61], The liquid heat capacity of iso-alkanes is calculated using Equation (10). Following [1,58,63], the liquid thermal conductivity of iso-alkanes was estimated using the Latini formula (Equations (11) and (12)).

\section{B.5. Enthalpy of evaporation and saturated vapour pressure}

The enthalpy of evaporation was estimated using Equation (14) with coefficients $A$ and $B$ given in Table 9. Following $[58,65]$, as in the case on n-alkanes, the saturated vapour pressure of iso-alkanes was calculated from Equation (13).

\section{Transport and thermodynamic properties of aromatics}

\section{C.1. Molecular structure, boiling and critical temperatures}

Using data from [56,57], the dependence of boiling temperature at atmospheric pressure, critical temperature and pressures on $n$ in the range $8 \leq n \leq 11$ were approximated as:.

$$
T_{b}=-1.4662 n^{2}+46.596 n+136.63 \quad(\mathrm{~K})
$$

$T_{c r}=0.0257 n^{2}+15.718 n+499.56 \quad(\mathrm{~K})$

$P_{c r}=0.7329 n^{2}-17.615 n+131.36 \quad$ (bar).

Errors of these approximations were shown to be $2.77 \%, 3.22 \%$ and $0.26 \%$ respectively. 


\section{C.2. Liquid density, viscosity, heat capacity and thermal conductivity}

The liquid density was estimated using Equation (8) with the values of coefficients given in Table 10. The liquid viscosity was estimated using Equation (9) with the coefficients given in Table 11. Following [59-61], the liquid heat capacity was calculated using Equation (10). Following [1,58,63], the liquid thermal conductivity was estimated using the Latini formula with the coefficients given in Table 6.

\section{C.3. Enthalpy of evaporation and saturated vapour pressure}

The latent heat of evaporation was estimated from Equation (14), using the coefficients given in Table 12. Following $[58,65]$, the saturated vapour pressure of aromatics was calculated from Equation (13) with the critical pressures given by Equation (19).

\section{Transport and thermodynamic properties of indanes/naphthalenes, cycloalkanes and ole-}

fins

\section{D.1. Molecular structure, boiling and critical temperatures}

The boiling temperature at atmospheric pressure, critical temperature and pressure of characteristic components of indanes/naphthalenes $\left(\mathrm{C}_{9} \mathrm{H}_{10}\right)$, cycloalkanes (cis-1-ethyl-3-methylcyclopentane; $\left.\mathrm{C}_{8} \mathrm{H}_{16}\right)$, and olefins (1-nonene; $\mathrm{C}_{9} \mathrm{H}_{18}$ ) are the following [56-58,66]:

$T_{b}=451.12 \mathrm{~K}, T_{c r}=684.9 \mathrm{~K}$ and $P_{c r}=39.50$ bar, for indane $\left(\mathrm{C}_{9} \mathrm{H}_{10}\right)$;

$T_{b}=394.25 \mathrm{~K}, T_{c r}=586.99 \mathrm{~K}$ and $P_{c r}=29.57$ bar, for cis-1-ethyl-3-methylcyclopentane;

$T_{b}=420.02 \mathrm{~K}, T_{c r}=594 \mathrm{~K}$ and $P_{c r}=23.30 \mathrm{bar}$, for 1 -nonene.

\section{D.2. Liquid density, viscosity, heat capacity and thermal conductivity}

The liquid densities of the characteristic components for indanes/naphthalenes, cycloalkanes and olefins are calculated using Equation (8) with the coefficients $A, B$ and $C$ given in Table 13. The liquid viscosities of the characteristic components for indanes/naphthalenes, cycloalkanes and olefins were estimated using Expression (9) with the coefficients given in Table 14. Following [59-61], the liquid heat capacity of the characteristic components for indanes/naphthalenes, cycloalkanes and olefins were calculated using Equation (10) with the coefficients given in Table 5. Following $[1,58,63]$, the liquid thermal conductivities of the characteristic components for indanes/naphthalenes, cycloalkanes and olefins were estimated using the Latini formula (Equations (11) and (12)) with the coefficients given in Table 6. 
Following [58,65], the saturated vapour pressures of the characteristic components for indanes/naphthalenes,

cycloalkanes and olefins were calculated from Equation (13). The latent heats of evaporation of the characteristic components for indanes/naphthalenes, cycloalkanes and olefins were calculated using Equation (14) with coefficients $A$ and $B$ given in Table 15 .

\section{References}

[1] Sawyer RF. Trends in auto emissions and gasoline composition. Environ Health Perspect 1993;101:5-12.

[2] Sarathy SM, Kukkadapu G, Mehl M, Wang W, Javed T, Park S, et al. Ignition of alkane-rich FACE gasoline fuels and their surrogate mixtures. Proceedings of the Combustion Institute 2015;35:249-57. doi:10.1016/j.proci.2014.05.122.

[3] Elwardany AE, Sazhin SS, Farooq A. Modelling of heating and evaporation of gasoline fuel droplets: A comparative analysis of approximations. Fuel 2013;111:643-7. doi:10.1016/j.fuel.2013.03.030.

[4] Teng ST, Williams AD, Urdal K. Detailed hydrocarbon analysis of gasoline by GC-MS (SI-PIONA). Journal of High Resolution Chromatography 1994;17:469-75. doi:10.1002/jhrc.1240170614.

[5] Abramzon B, Sazhin SS. Convective vaporization of a fuel droplet with thermal radiation absorption. Fuel 2006;85:32-46. doi:10.1016/j.fuel.2005.02.027.

[6] Sirignano WA. Fluid Dynamics and Transport of Droplets and Sprays. Cambridge, U.K: Cambridge University Press; 1999.

[7] Abramzon B, Sazhin S. Droplet vaporization model in the presence of thermal radiation. International Journal of Heat and Mass Transfer 2005;48:1868-73. doi:10.1016/j.ijheatmasstransfer.2004.11.017.

[8] Elwardany AE, Sazhin SS. A quasi-discrete model for droplet heating and evaporation: Application to Diesel and gasoline fuels. Fuel 2012;97:685-94. doi:10.1016/j.fuel.2012.01.068.

[9] Elwardany AE, Gusev IG, Castanet G, Lemoine F, Sazhin SS. Mono- and multi-component droplet cooling/heating and evaporation: comparative analysis of numerical models. Atomization and Sprays 2011;21:907-31. doi:10.1615/AtomizSpr.2012004194.

[10] Sazhin SS. Advanced models of fuel droplet heating and evaporation. Progress in Energy and Combustion Science 2006;32:162-214. doi:10.1016/j.pecs.2005.11.001.

[11] Sazhin SS, Al Qubeissi M, Kolodnytska R, Elwardany AE, Nasiri R, Heikal MR. Modelling of biodiesel fuel droplet heating and evaporation. Fuel 2014;115:559-72. doi:10.1016/j.fuel.2013.07.031.

[12] Sazhin SS, Elwardany AE, Sazhina EM, Heikal MR. A quasi-discrete model for heating and evaporation of complex multicomponent hydrocarbon fuel droplets. International Journal of Heat and Mass Transfer 2011;54:4325-32. doi:10.1016/j.ijheatmasstransfer.2011.05.012.

[13] Sazhin SS, Al Qubeissi M, Nasiri R, Gun'ko VM, Elwardany AE, Lemoine F, et al. A multi-dimensional quasidiscrete model for the analysis of Diesel fuel droplet heating and evaporation. Fuel 2014;129:238-66. doi:10.1016/j.fuel.2014.03.028.

[14] Sazhin SS, Shishkova IN, Al Qubeissi M. Heating and evaporation of a two-component droplet: Hydrodynamic and kinetic models. International Journal of Heat and Mass Transfer 2014;79:704-12. doi:10.1016/j.ijheatmasstransfer.2014.08.026.

[15] Sazhin SS, Al Qubeissi M, Xie J-F. Two approaches to modelling the heating of evaporating droplets. International Communications in Heat and Mass Transfer 2014;57:353-6. doi:10.1016/j.icheatmasstransfer.2014.08.004.

[16] Sazhin SS. Droplets and Sprays. London: Springer; 2014.

[17] Ma X, Jiang C, Xu H, Ding H, Shuai S. Laminar burning characteristics of 2-methylfuran and isooctane blend fuels. Fuel 2014;116:281-91. doi:10.1016/j.fuel.2013.08.018.

[18] Paxson FL. The Last American Frontier. Simon Publications LLC; 2001.

[19] Sazhin SS, Kristyadi T, Abdelghaffar WA, Begg S, Heikal MR, Mikhalovsky SV, et al. Approximate Analysis of Thermal Radiation Absorption in Fuel Droplets. Journal of Heat Transfer 2007;129:1246. doi:10.1115/1.2740304.

[20] Pitz WJ, Cernansky NP, Dryer FL, Egolfopoulos FN, Farrell JT, Friend DG, et al. Development of an Experimental Database and Chemical Kinetic Models for Surrogate Gasoline Fuels. Warrendale, PA: SAE International; 2007.

[21] Abraham J, Magi V. A Model for Multicomponent Droplet Vaporization in Sprays. Warrendale, PA: SAE International; 1998. 
[22] Aggarwal SK, Mongia HC. Multicomponent and High-Pressure Effects on Droplet Vaporization. Journal of Engineering for Gas Turbines and Power 2002;124:248. doi:10.1115/1.1423640.

[23] Continillo G, Sirignano WA. Unsteady, Spherically-Symmetric Flame Propagation Through Multicomponent Fuel Spray Clouds. In: Angelino G, Luca LD, Sirignano WA, editors. Modern Research Topics in Aerospace Propulsion, Springer New York; 1991, p. 173-98.

[24] Klingsporn M, Renz U. Vaporization of a binary unsteady spray at high temperature and high pressure. International Journal of Heat and Mass Transfer 1994;37:265-72. doi:10.1016/0017-9310(94)90027-2.

[25] Lage PLC, Hackenberg CM, Rangel RH. Nonideal vaporization of dilating binary droplets with radiation absorption. Combustion and Flame 1995;101:36-44. doi:10.1016/0010-2180(94)00191-T.

[26] Maqua C, Castanet G, Lemoine F. Bicomponent droplets evaporation: Temperature measurements and modelling. Fuel 2008;87:2932-42. doi:10.1016/j.fuel.2008.04.021.

[27] Ra Y, Reitz RD. A vaporization model for discrete multi-component fuel sprays. International Journal of Multiphase Flow 2009;35:101-17. doi:10.1016/j.ijmultiphaseflow.2008.10.006.

[28] Tong AY, Sirignano WA. Multicomponent Transient Droplet Vaporization with Internal Circulation: Integral Equation Formulation and Approximate Solution. Numerical Heat Transfer 1986;10:253-78. doi:10.1080/10407788608913519.

[29] Abdel-Qader Z, Hallett WLH. The role of liquid mixing in evaporation of complex multicomponent mixtures: modelling using continuous thermodynamics. Chemical Engineering Science 2005;60:1629-40. doi:10.1016/j.ces.2004.10.015.

[30] Arias-Zugasti M, Rosner DE. Multicomponent fuel droplet vaporization and combustion using spectral theory for a continuous mixture. Combustion and Flame 2003;135:271-84. doi:10.1016/S0010-2180(03)00166-4.

[31] Hallett WLH. A simple model for the vaporization of droplets with large numbers of components. Combustion and Flame 2000;121:334-44. doi:10.1016/S0010-2180(99)00144-3.

[32] Lippert AM, Reitz RD. Modeling of multicomponent fuels using continuous distributions with application to droplet evaporation and sprays. Warrendale, PA: SAE International; 1997.

[33] Rivard E, Brüggemann D. Numerical investigation of semi-continuous mixture droplet vaporization at low temperature. Chemical Engineering Science 2010;65:5137-45. doi:10.1016/j.ces.2010.06.010.

[34] Tamim J, Hallett WLH. A continuous thermodynamics model for multicomponent droplet vaporization. Chemical Engineering Science 1995;50:2933-42. doi:10.1016/0009-2509(95)00131-N.

[35] Zhang L, Kong S-C. Modeling of multi-component fuel vaporization and combustion for gasoline and diesel spray. Chemical Engineering Science 2009;64:3688-96. doi:10.1016/j.ces.2009.05.013.

[36] Zhu G-S, Reitz RD. A model for high-pressure vaporization of droplets of complex liquid mixtures using continuous thermodynamics. International Journal of Heat and Mass Transfer 2002;45:495-507. doi:10.1016/S0017-9310(01)00173-9.

[37] Burger M, Schmehl R, Prommersberger K, Schäfer O, Koch R, Wittig S. Droplet evaporation modeling by the distillation curve model: accounting for kerosene fuel and elevated pressures. International Journal of Heat and Mass Transfer 2003;46:4403-12. doi:10.1016/S0017-9310(03)00286-2.

[38] Ott LS, Smith BL, Bruno TJ. Composition-Explicit Distillation Curves of Waste Lubricant Oils and Resourced Crude Oil: A Diagnostic for Re-Refining and Evaluation. American Journal of Environmental Sciences 2010;6:523-34. doi:10.3844/ajessp.2010.523.534.

[39] Smith BL, Bruno TJ. Advanced Distillation Curve Measurement with a Model Predictive Temperature Controller. Int J Thermophys 2006;27:1419-34. doi:10.1007/s10765-006-0113-7.

[40] Al Qubeissi M, Kolodnytska R, Sazhin SS. Biodiesel fuel droplets: modelling of heating and evaporation processes. 25th European Conference on Liquid Atomization and Spray Systems, vol. 4 (CD), Crete, Greece: 2013.

[41] Elwardany AE. Modelling of multi-component fuel droplets heating and evaporation. PhD thesis. University of Brighton, 2012.

[42] Laurent C, Lavergne G, Villedieu P. Continuous thermodynamics for droplet vaporization: Comparison between Gamma-PDF model and QMoM. Comptes Rendus Mécanique 2009;337:449-57. doi:10.1016/j.crme.2009.06.004.

[43] Zhang L, Kong S-C. Vaporization modeling of petroleum-biofuel drops using a hybrid multi-component approach. Combustion and Flame 2010;157:2165-74. doi:10.1016/j.combustflame.2010.05.011.

[44] Zhang L. Multicomponent drop vaporization modeling of petroleum and biofuel mixtures. Iowa State University, 2011.

[45] Tonini S, Gavaises M, Arcoumanis C, Theodorakakos A, Kometani S. Multi-component fuel vaporization modelling and its effect on spray development in gasoline direct injection engines. Proceedings of the Institution of Mechanical Engineers, Part D: Journal of Automobile Engineering 2007;221:1321-42. doi:10.1243/09544070JAUT0545.

[46] Strotos G, Gavaises M, Theodorakakos A, Bergeles G. Numerical investigation of the evaporation of two-component droplets. Fuel 2011;90:1492-507. doi:10.1016/j.fuel.2011.01.017.

[47] Al Qubeissi M, Sazhin SS, de Sercey G, Crua C. Multi-dimensional quasi-discrete model for the investigation of heating and evaporation of Diesel fuel droplets. 26th European Conference on Liquid Atomization and Spray Systems, vol. ABS-135 (CD), Bremen, Germany: University of Bremen; 2014. 
[48] Abramzon B, Sirignano WA. Droplet vaporization model for spray combustion calculations. International Journal of Heat and Mass Transfer 1989;32:1605-18. doi:10.1016/0017-9310(89)90043-4.

[49] Al Qubeissi M, Sazhin SS, Crua C, Heikal MR. Modelling of Heating and Evaporation of Biodiesel Fuel Droplets. WASET, Int J Mech Aero Ind Mechat Eng 2015;9:46-9.

[50] Sazhin SS, Elwardany AE, Krutitskii PA, Deprédurand V, Castanet G, Lemoine F, et al. Multi-component droplet heating and evaporation: Numerical simulation versus experimental data. International Journal of Thermal Sciences 2011;50:1164-80. doi:10.1016/j.ijthermalsci.2011.02.020.

[51] Sazhin SS, Abdelghaffar WA, Krutitskii PA, Sazhina EM, Heikal MR. New approaches to numerical modelling of droplet transient heating and evaporation. International Journal of Heat and Mass Transfer 2005;48:4215-28. doi:10.1016/j.ijheatmasstransfer.2005.04.007.

[52] Sazhin SS, Kristyadi T, Abdelghaffar WA, Heikal MR. Models for fuel droplet heating and evaporation: Comparative analysis. Fuel 2006;85:1613-30. doi:10.1016/j.fuel.2006.02.012.

[53] Tonini S, Cossali GE. An analytical model of liquid drop evaporation in gaseous environment. International Journal of Thermal Sciences 2012;57:45-53. doi:10.1016/j.ijthermalsci.2012.01.017.

[54] Rogers MC, Brown GG. Raoult's Law and the Equilibrium Vaporization of Hydrocarbon Mixtures. University of Michigan; 1929.

[55] Sazhin SS, Elwardany A, Krutitskii PA, Castanet G, Lemoine F, Sazhina EM, et al. A simplified model for bicomponent droplet heating and evaporation. International Journal of Heat and Mass Transfer 2010;53:4495-505. doi:10.1016/j.ijheatmasstransfer.2010.06.044.

[56] Yaws CL. Thermophysical Properties of Chemicals and Hydrocarbons. Norwich, NY: William Andrew; 2008.

[57] Yaws CL. Thermophysical properties of chemicals and hydrocarbons. 2nd ed. Oxford, UK: 2014.

[58] Poling BE, Prausnitz JM, O’Connell JP. The Properties of Gases and Liquids. New York: McGraw-Hill; 2001.

[59] Dadgostar N, Shaw JM. A predictive correlation for the constant-pressure specific heat capacity of pure and ill-defined liquid hydrocarbons. Fluid Phase Equilibria 2012;313:211-26. doi:10.1016/j.fluid.2011.09.015.

[60] Lee BI, Kesler MG. Private Communication. Princeton, N.J.: Mobil Oil Corporation; 1975.

[61] Lee BI, Kesler MG. A generalized thermodynamic correlation based on three-parameter corresponding states. AIChE J 1975;21:510-27. doi:10.1002/aic.690210313.

[62] Gharagheizi F, Fazeli A. Prediction of the Watson Characterization Factor of Hydrocarbon Components from Molecular Properties. QSAR Comb Sci 2008;27:758-67. doi:10.1002/qsar.200730020.

[63] Latini G, Cocci Grifoni R, Passerini G, editors. Transport properties of organic liquids. Southampton ; Boston: WIT Press; 2006.

[64] Latini G, Cocci Grifoni R, Passerini G, editors. Transport Properties of Organic Liquids. Southampton ; Boston: WIT Press; 2006.

[65] Komkoua Mbienda AJ, Tchawoua C, Vondou DA, Mkankam Kamga F. Evaluation of Vapor Pressure Estimation Methods for Use in Simulating the Dynamic of Atmospheric Organic Aerosols. International Journal of Geophysics 2013;2013:e612375. doi:10.1155/2013/612375.

[66] Yaws CL. The Yaws handbook of vapor pressure: Antoine coefficients. Houston, Tex.: Gulf Pub.; 2007.

[67] ChemSpider 2014. http://www.chemspider.com/ (accessed December 30, 2014).

\section{Figure captions}

Fig. 1 The structures of some organic components of gasoline fuel, generated using software [67].

Fig. 2 The droplet surface temperatures $T_{s}$ and radii $R_{d}$ versus time for the cases when 1) the contributions of all 20 components are taken into account using the ETC/ED model (ME); 2) the contribution of 20 components are taken into account using the ITC/ID model (MI), 3) the 20 component are approximated by a single component with average thermodynamic and transport properties in combination with the ITC model (SI); 4) gasoline fuel is approximated by iso-octane in combination with the ITC model (IO). The droplet with the initial radius $12 \mu \mathrm{m}$ and initial homogeneous temperature $296 \mathrm{~K}$ is assumed to be moving with relative velocity $24 \mathrm{~m} / \mathrm{s}$ in air. Ambient pressure and temperature are equal to $0.9 \mathrm{MPa}$ and $545 \mathrm{~K}$ respectively. 
Fig. 3 The same as Fig. 2 but for the cases when the ETC/ED model was used taking into account the contributions of all 20 components of gasoline fuel (indicated as ME) and assuming that these components are approximated by 15, 11 and 7 quasi-components/components (QC/C) (numbers are indicated near the plots).

Fig. 4 The same as Fig. 3 but for the cases when 20 components of gasoline fuel are approximated by 6, 5, 4 and 3 quasi-components/components (QC/C).

Fig. 5 The zoomed parts of Fig. 4.

Fig. 6 The surface mass fractions $Y_{\text {lis }}$ versus time for $\mathrm{C}_{5} \mathrm{H}_{12}(1), \mathrm{C}_{12} \mathrm{H}_{26}$ (2), iso $-\mathrm{C}_{7} \mathrm{H}_{16}$ (3), iso $-\mathrm{C}_{8} \mathrm{H}_{18}(4)$, iso $\mathrm{C}_{10} \mathrm{H}_{22}(5), \mathrm{C}_{9} \mathrm{H}_{12}(6), \mathrm{C}_{10} \mathrm{H}_{14}$ (7) and indane $\mathrm{C}_{9} \mathrm{H}_{10}$ (appproximation for indanes/naphthenes) (8), predicted by the ETC/ED model taking into account the contributions of all 20 components of gasoline fuel.

Fig. 7 Mass fractions of $n$-pentane $\mathrm{C}_{5} \mathrm{H}_{12}(\mathrm{~N})$ and propylbenzene $\mathrm{C}_{9} \mathrm{H}_{12}(\mathrm{P})$ versus normalised distance from the centre of droplet $\left(R / R_{d}\right)$ at four time instants, $0.02 \mathrm{~ms}, 0.3 \mathrm{~ms}, 0.5 \mathrm{~ms}$ and $1 \mathrm{~ms}$ (indicated near the plots), predicted by the ETC/ED model taking into account the contributions of all 20 components of gasoline fuel.

Fig. 8 The plots of temperature versus normalised distance from the droplet centre $\left(R / R_{d}\right)$ at three instants of time $0.02 \mathrm{~ms}, 0.3 \mathrm{~ms}$ and $0.5 \mathrm{~ms}$ (indicated near the plots) as predicted by the ETC/ED model, taking into account the contributions of all 20 components.

Fig. 9 The droplet radii versus the number of $\mathrm{QC} / \mathrm{C}$, used for the approximation of gasoline fuel, at four time instants, $0.5 \mathrm{~ms}, 1.5 \mathrm{~ms}, 3 \mathrm{~ms}$, and $4 \mathrm{~ms}$.

Fig. 10 The droplet surface temperatures versus the number of $\mathrm{QC} / \mathrm{C}$, used for the approximation of gasoline fuel, at four time instants, $0.5 \mathrm{~ms}, 1.5 \mathrm{~ms}, 3 \mathrm{~ms}$, and $4 \mathrm{~ms}$.

Fig. 11 Plot of CPU time required for calculations of droplet heating and evaporation versus the number of QC/C used in the model for the same input parameters as in Figs. 2-10.

\section{Table captions}

Table 1 The original and simplified compositions of gasoline fuel used in the analysis.

Table 2 The groups of component of gasoline fuel, their molar fractions, and the numbers of components in the groups, as inferred from Table 1.

Table 3 The numbers of QC/C in various groups of components compared to the total numbers of QC/C.

Table 4 The coefficients used in Equation (8) for estimating the liquid viscosity of n-alkanes.

Table 5 The carbon numbers and relative densities of components at $288.706 \mathrm{~K}$.

Table 6 The coefficients used in Equation (11) for six groups of components.

Table 7 The coefficients used in Equation (16) for estimation of the enthalpy of evaporation of iso-alkanes.

Table 8 The coefficients used in Equation (8) for estimating the liquid viscosity of iso-alkanes 
515 Table 9 The coefficients used in Equation (16) for estimating the enthalpy of evaporation of iso-alkanes.

516 Table 10 The coefficients used in Equation (7) for the estimation of the liquid density of aromatics.

517 Table 11 The coefficients used in Equation (8) for estimating the liquid viscosity of aromatics.

518 Table 12 The coefficients used in Equation (16) for estimation of the enthalpy of evaporation of aromatics.

519 Table 13 The coefficients used in Equation (7) for the estimation of the liquid density of three characteristic com-

520 ponents for indanes/naphthalenes, cycloalkanes and olefins.

521 Table 14 The coefficients used in Equation (8) for estimating the liquid viscosity of the characteristic components

522 for indanes/naphthalenes, cycloalkanes and olefins.

523 Table 15 The coefficients used in Equation (16) for estimation of the enthalpy of evaporation of three characteristic

524 components for indanes/naphthalenes, cycloalkanes and olefins. 


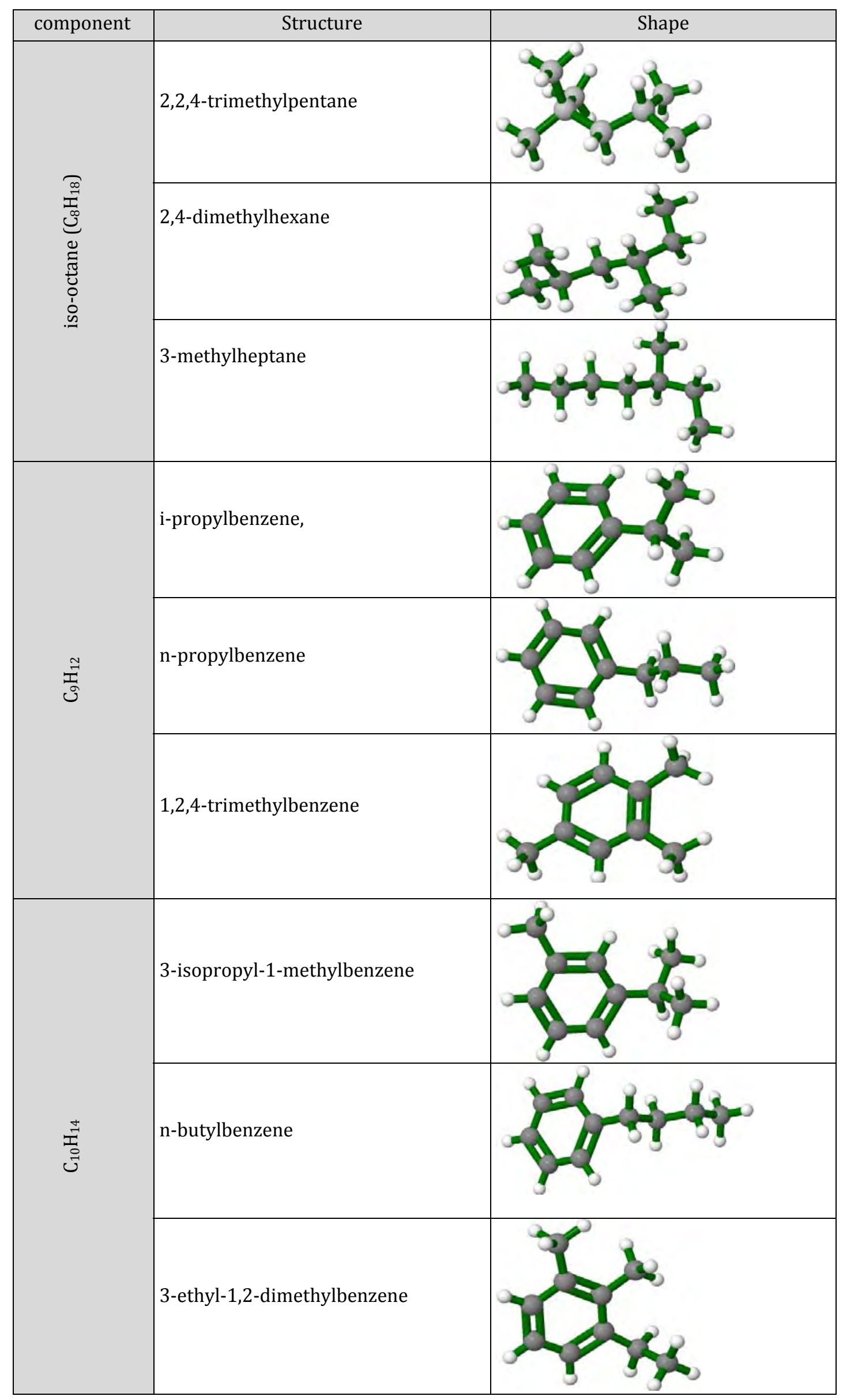

Fig. 1 


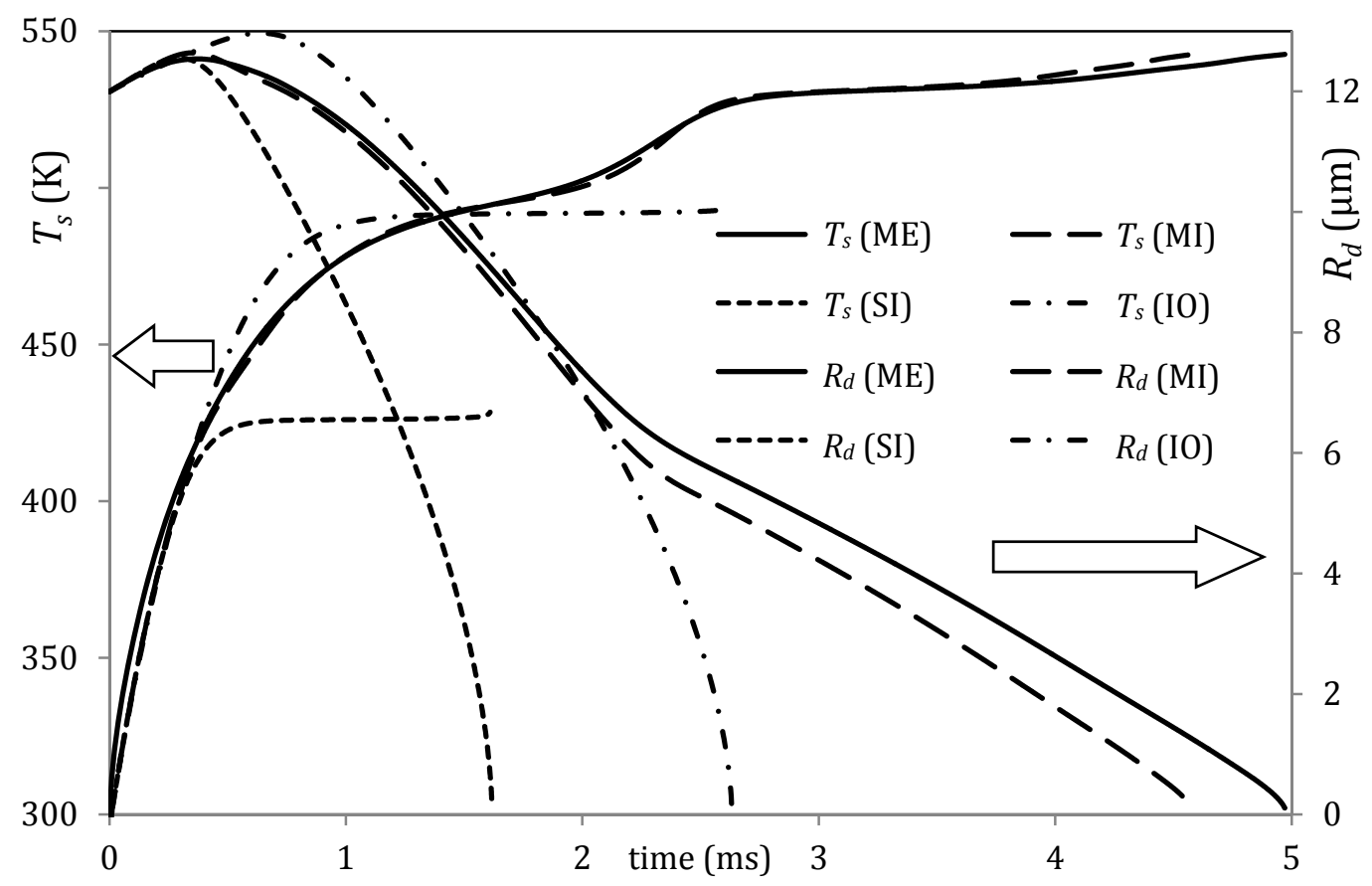

Fig. 2

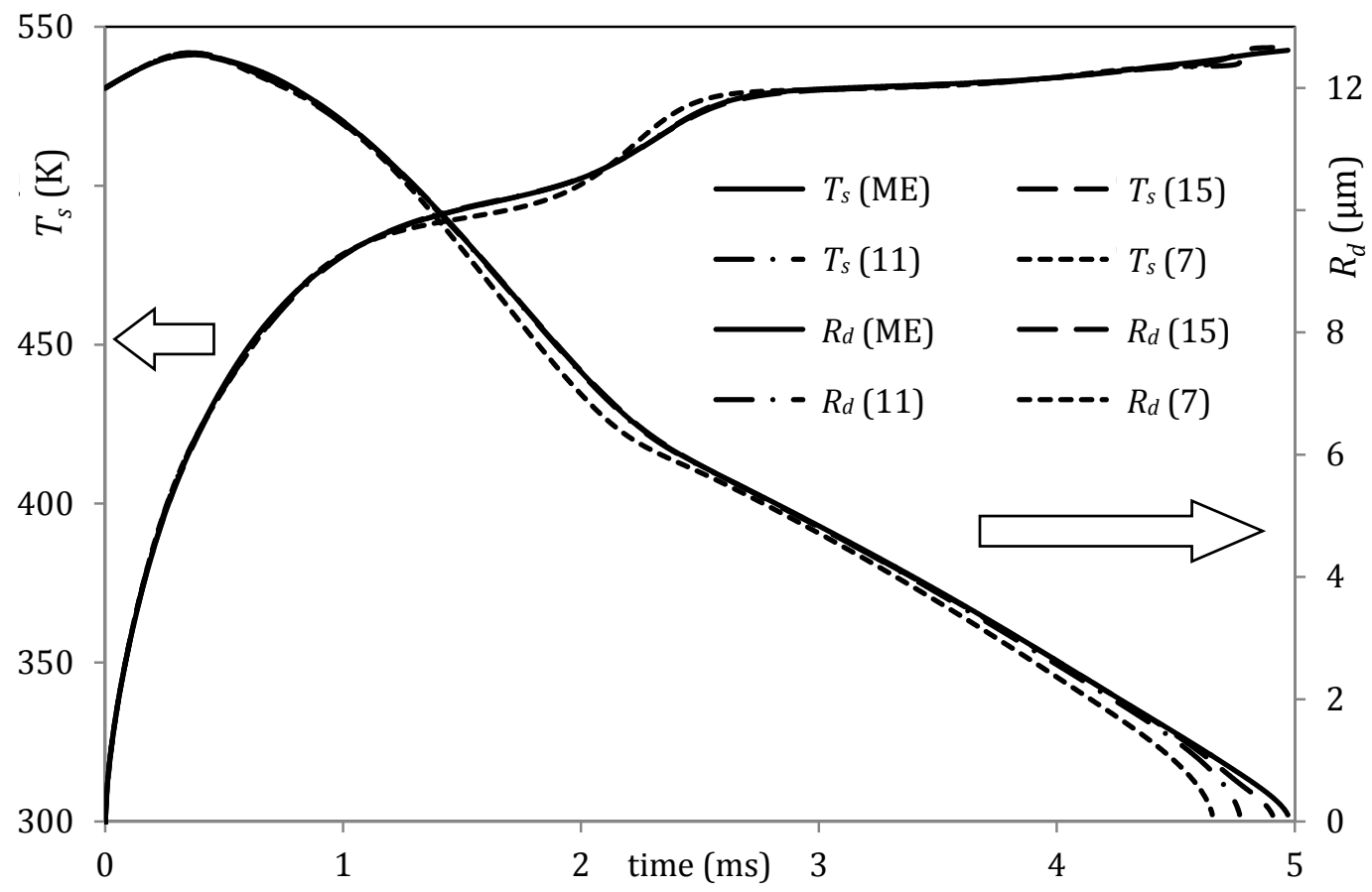

Fig. 3 


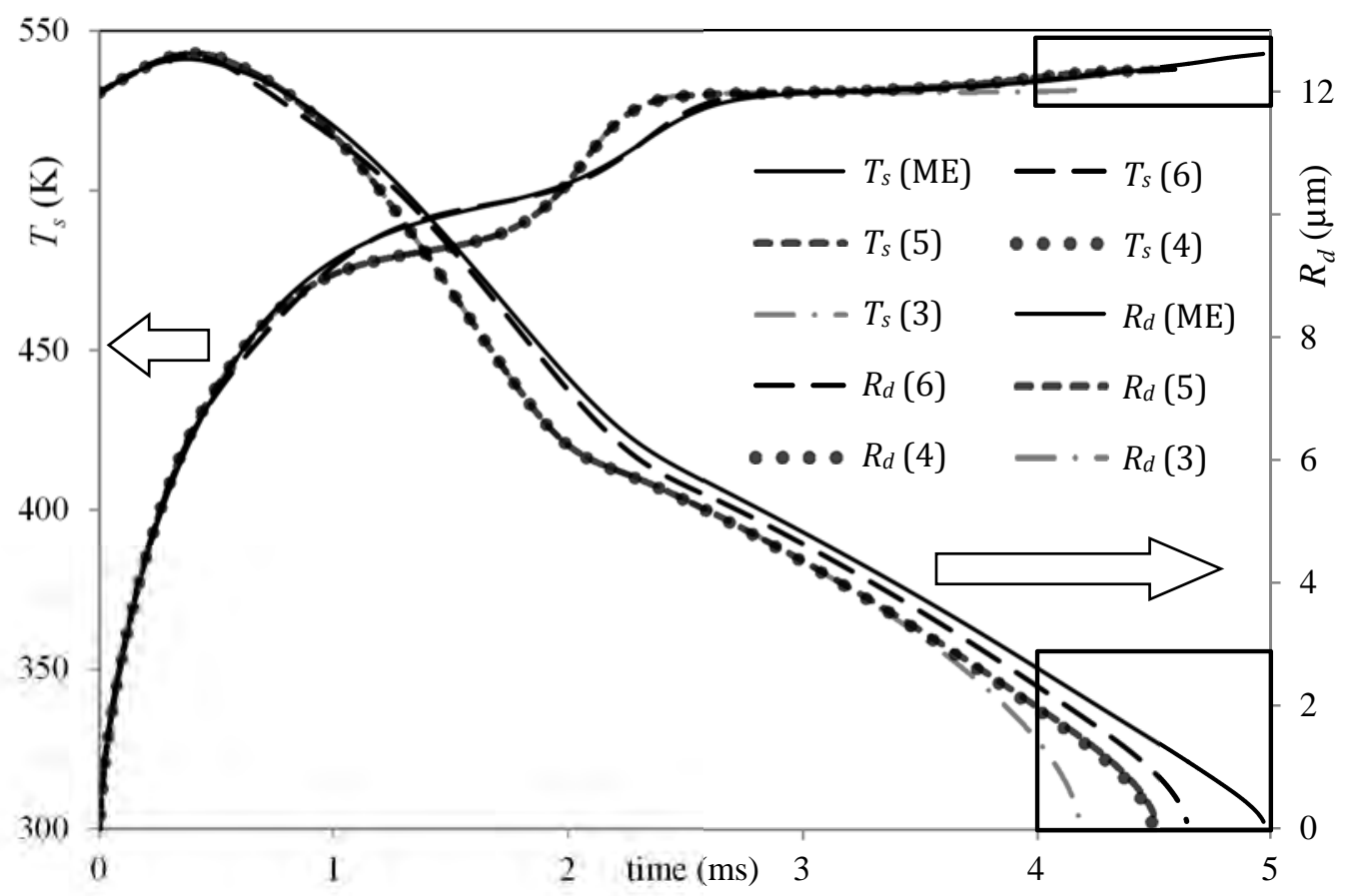

Fig. 4

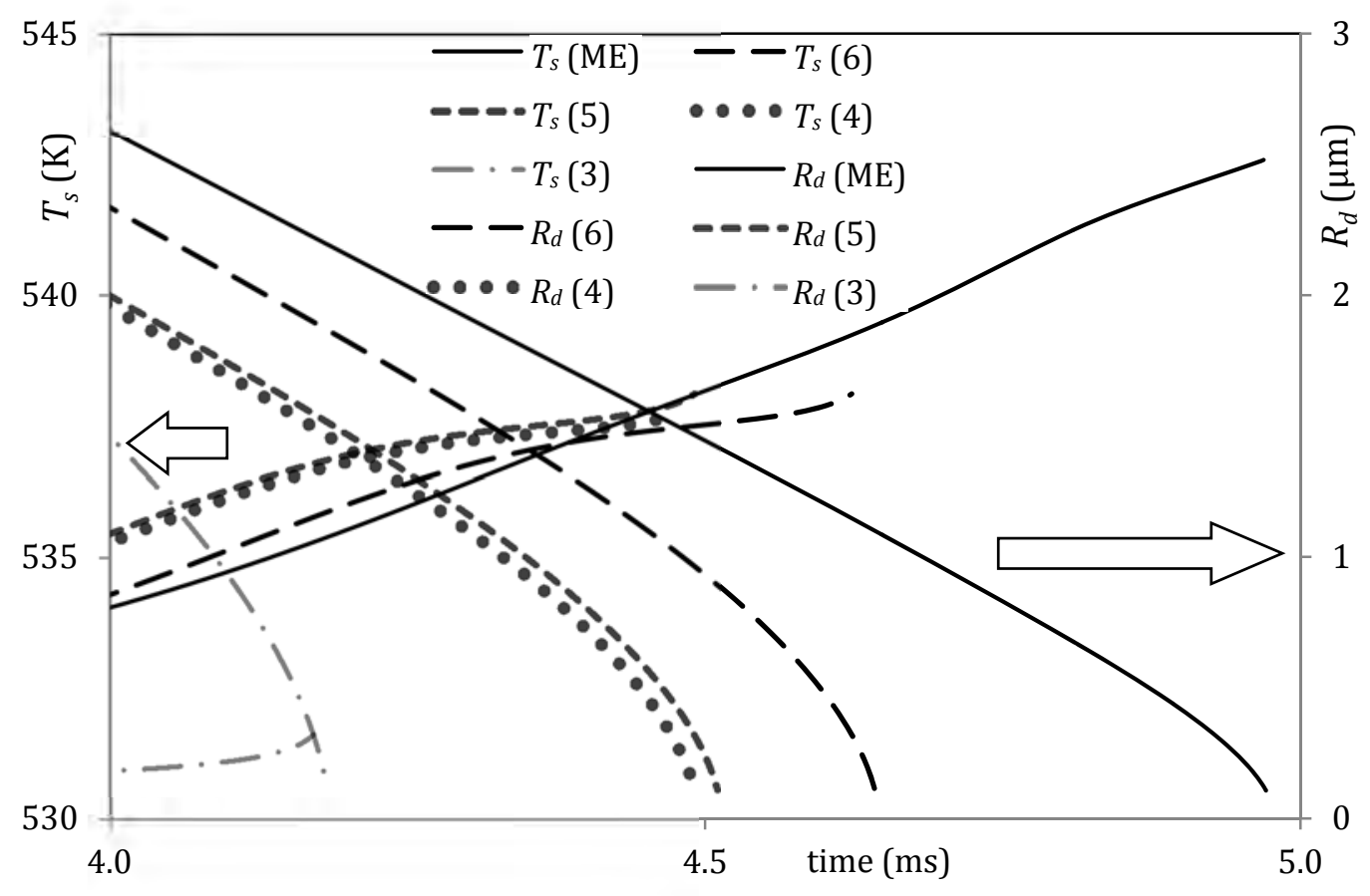

Fig. 5 


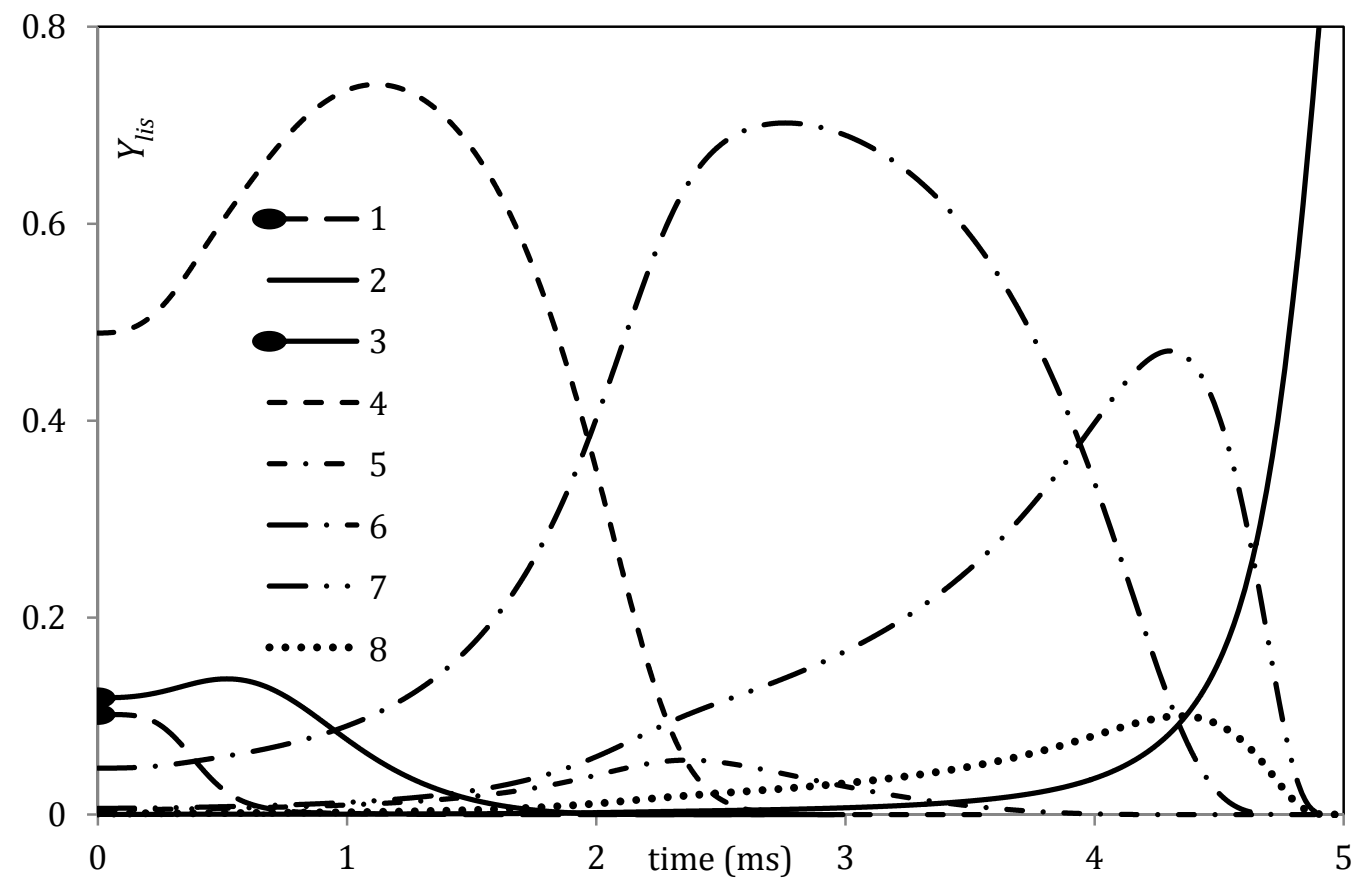

Fig. 6

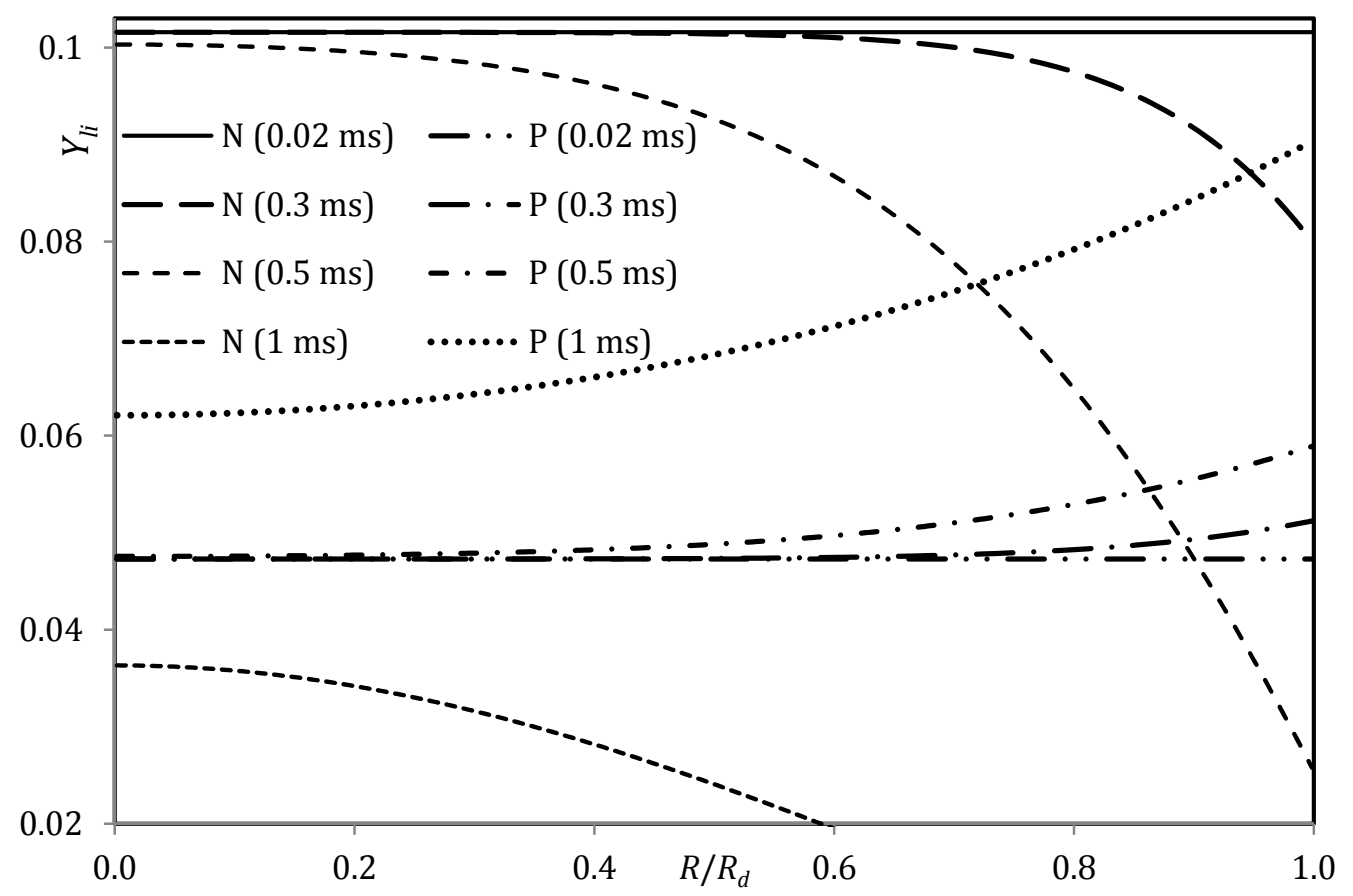

Fig. 7 


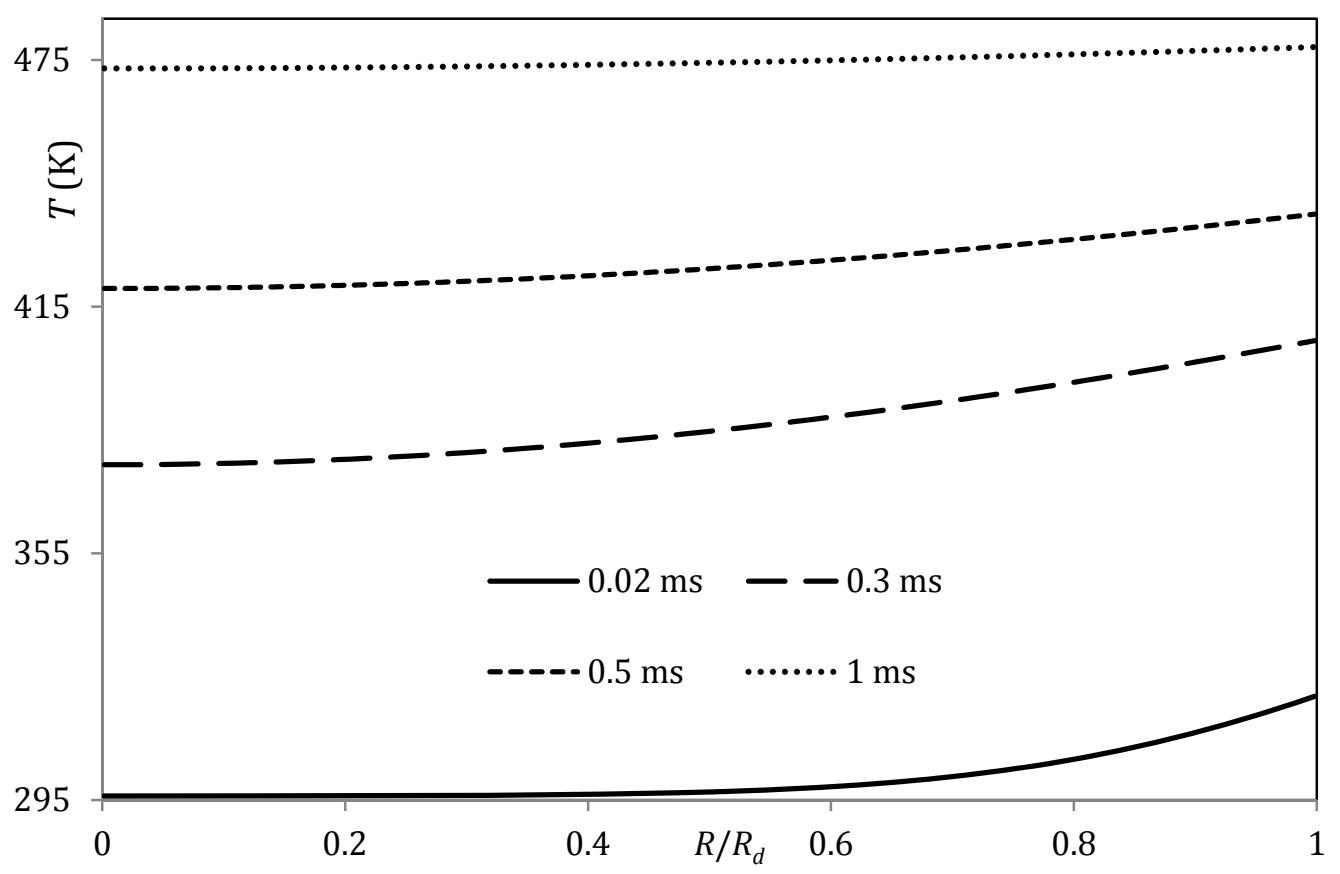

Fig. 8
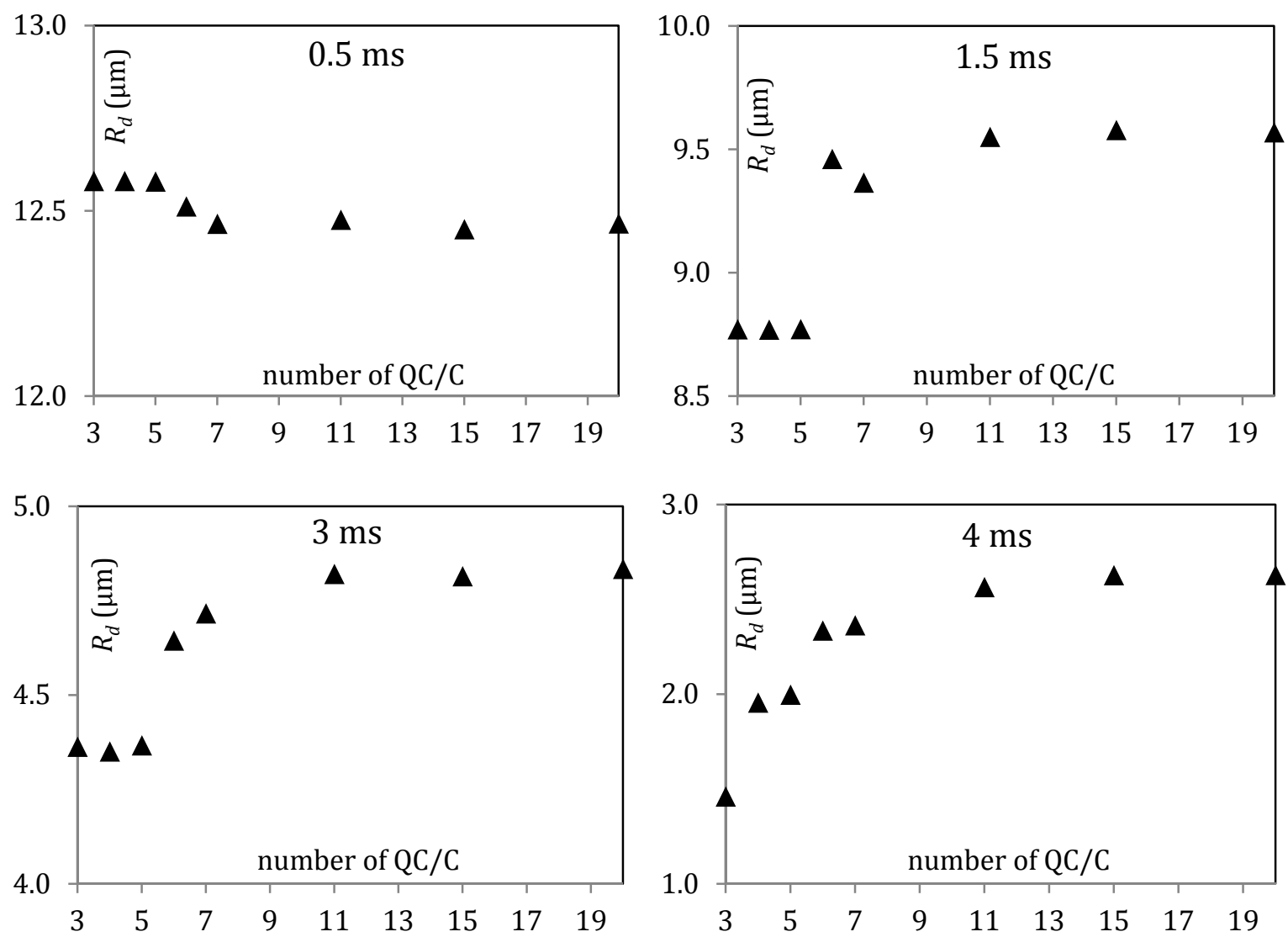

Fig. 9 

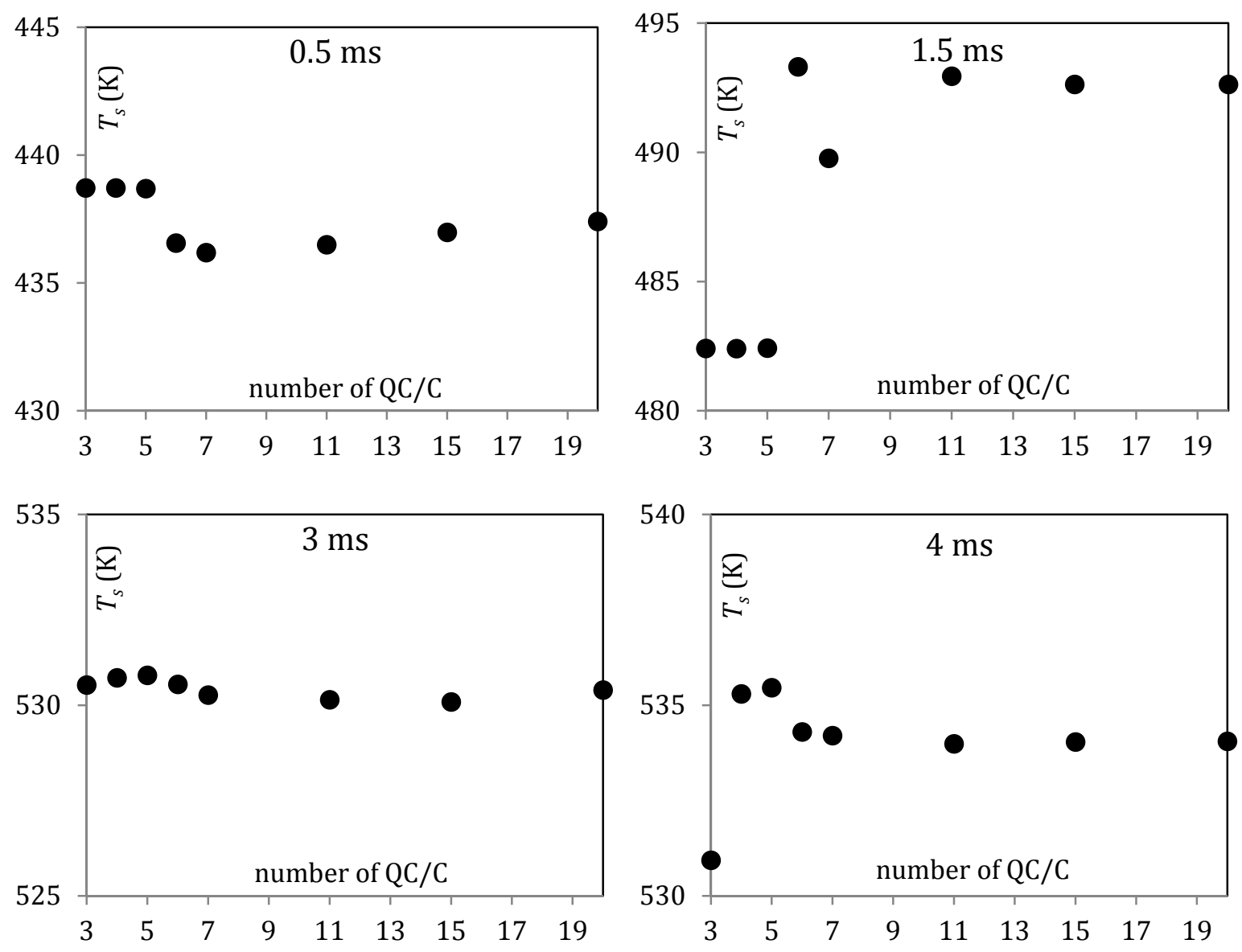

Fig. 10

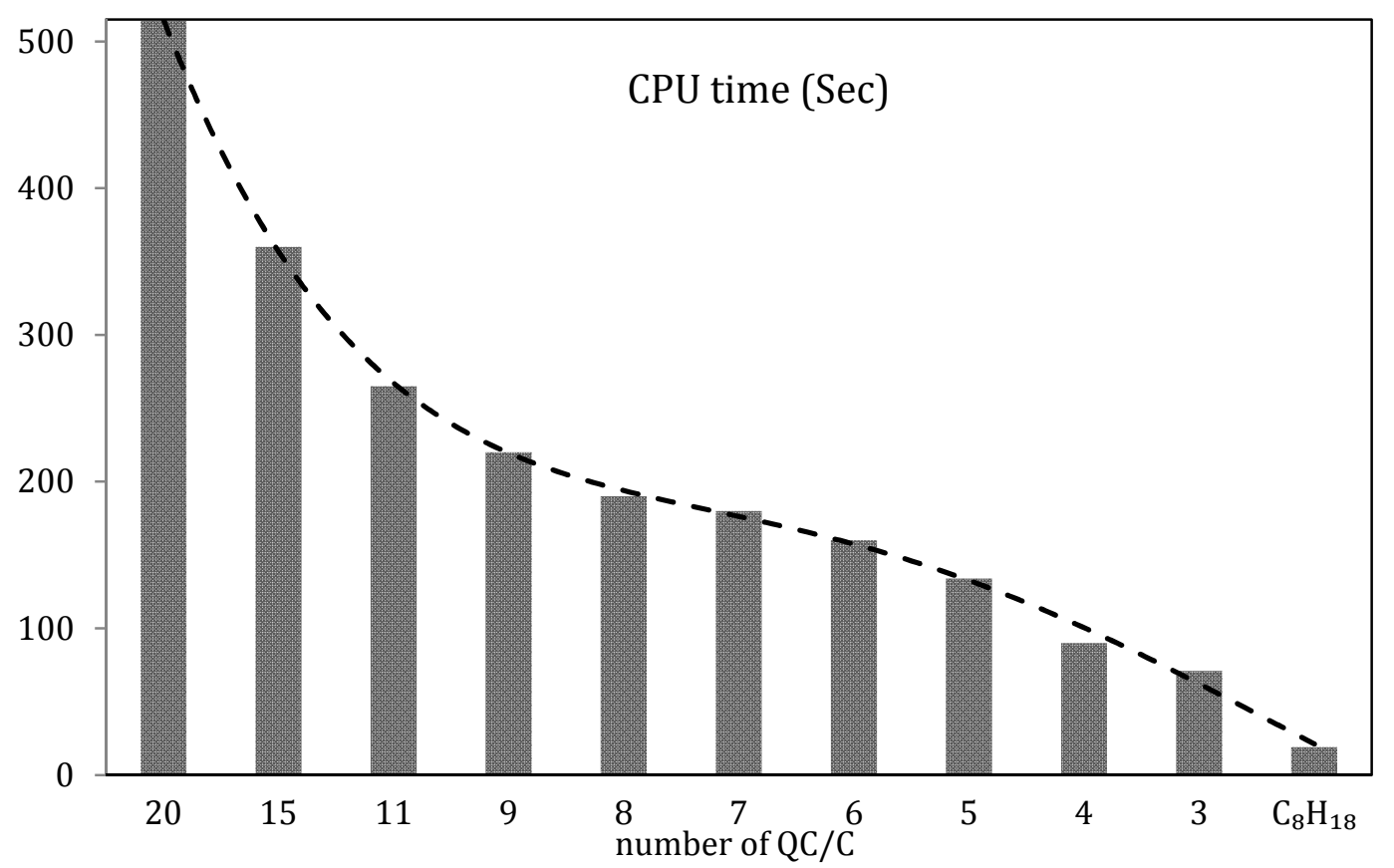

Fig. 11 
Table 1

\begin{tabular}{|c|c|c|c|c|c|}
\hline group & components & $\begin{array}{c}\text { carbon } \\
\text { numbers }\end{array}$ & $\begin{array}{c}\text { molar } \\
\text { fractions }(\%)\end{array}$ & approximations & $\begin{array}{c}\text { molar } \\
\text { fractions }(\%)\end{array}$ \\
\hline \multirow{5}{*}{ 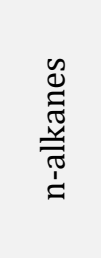 } & n-butane & 4 & 3.905436784 & same & 3.905436784 \\
\hline & n-pentane & 5 & 13.87020578 & same & 13.87020578 \\
\hline & n-hexane & 6 & 10.84154056 & same & 10.84154056 \\
\hline & n-decane & 10 & 0.010008808 & same & 0.010008808 \\
\hline & n-dodecane & 12 & 0.012010569 & same & 0.012010569 \\
\hline \multirow{39}{*}{ 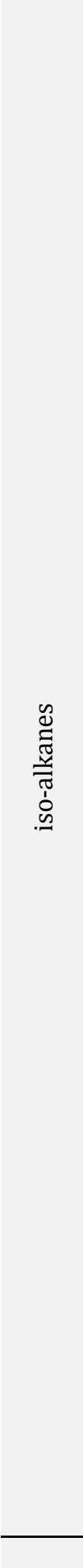 } & i-butane & 4 & 0.092081031 & same & 0.092081031 \\
\hline & 2,2-dimethylpropane & 5 & 0.012010569 & averaged & 7.456561774 \\
\hline & i-pentane & 5 & 7.444551205 & & \\
\hline & 2,3-dimethylbutane & 6 & 2.021779166 & & \\
\hline & 2-methylpentane & 6 & 0.604531988 & averaged & 2.979622067 \\
\hline & 3-methylpentane & 6 & 0.353310914 & & \\
\hline & 2,4-dimethylpentane & 7 & 4.271759148 & & \\
\hline & 2,2,3-trimethylbutane & 7 & 0.044038754 & & \\
\hline & 2-methylhexane & 7 & 0.253222836 & averaged & 11.66826808 \\
\hline & 2,3,-dimethylpentane & 7 & 6.883057090 & & \\
\hline & 3-methylhexane & 7 & 0.216190247 & & \\
\hline & 2,2,4-trimethylpentane & 8 & 23.23644807 & \multirow{13}{*}{ averaged } & \multirow{13}{*}{42.17311234} \\
\hline & 2,5-dimethylhexane & 8 & 1.739530787 & & \\
\hline & 2,2,3-trimethylpentane & 8 & 0.550484426 & & \\
\hline & 2,4-dimethylhexane & 8 & 2.369084795 & & \\
\hline & 2,3,4-trimethylpentane & 8 & 6.905076467 & & \\
\hline & 2,3,3-trimethylpentane & 8 & 4.947353671 & & \\
\hline & 2,3-dimethylhexane & 8 & 1.888662023 & & \\
\hline & 2-methyl-3-ethylpentane & 8 & 0.068059893 & & \\
\hline & 2-methylheptane & 8 & 0.060052847 & & \\
\hline & 4-methylheptane & 8 & 0.021018496 & & \\
\hline & 3-methyl-3-ethylpentane & 8 & 0.152133878 & & \\
\hline & 3,4-dimethylhexane & 8 & 0.175154136 & & \\
\hline & 3-methylheptane & 8 & 0.060052847 & & \\
\hline & 2,3,4-trimethylhexane & 9 & 0.179157659 & \multirow{4}{*}{ averaged } & \multirow{4}{*}{0.317279206} \\
\hline & 2,2,3-trimethylhexane & 9 & 0.02602290 & & \\
\hline & 2,5-dimethylheptane & 9 & 0.069060773 & & \\
\hline & 2,3,-dimethylheptane & 9 & 0.043037873 & & \\
\hline & c10 - isoparaffin-1 & 10 & 0.025022019 & \multirow{7}{*}{ averaged } & \multirow{7}{*}{0.360317079} \\
\hline & c10 - isoparaffin-2 & 10 & 0.128112739 & & \\
\hline & 3,3,5-trimethylheptane & 10 & 0.096084554 & & \\
\hline & 2,3,6-trimethylheptane & 10 & 0.05204580 & & \\
\hline & c10 - isoparaffin-1 & 10 & 0.016014092 & & \\
\hline & 2,6-dimethyloctane & 10 & 0.029025542 & & \\
\hline & c10 - isoparaffin-7 & 10 & 0.014012331 & & \\
\hline & $2,3,3$,trimethyloctane & 11 & 0.012010569 & \multirow{3}{*}{ averaged } & \multirow{3}{*}{0.113099528} \\
\hline & 2,5-dimethylnonane & 11 & 0.081071343 & & \\
\hline & 3-ethylnonane & 11 & 0.020017616 & & \\
\hline & o-xylene & 8 & 0.242213148 & same & 0.242213148 \\
\hline
\end{tabular}




\begin{tabular}{|c|c|c|c|c|c|}
\hline group & components & $\begin{array}{c}\text { carbon } \\
\text { numbers }\end{array}$ & $\begin{array}{c}\text { molar } \\
\text { fractions (\%) }\end{array}$ & approximations & $\begin{array}{c}\text { molar } \\
\text { fractions }(\%)\end{array}$ \\
\hline \multirow{23}{*}{ 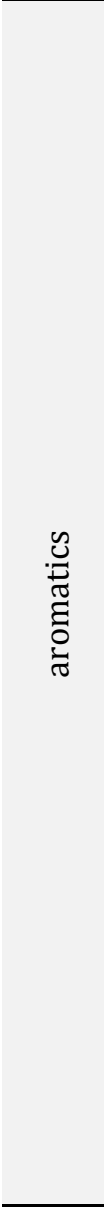 } & i-propylbenzene & 9 & 0.046040516 & \multirow{8}{*}{ averaged } & \multirow{8}{*}{3.521098567} \\
\hline & n-propylbenzene & 9 & 0.172151493 & & \\
\hline & 3-ethyl-1-methylbenzene & 9 & 0.621546961 & & \\
\hline & 4-ethyl-1-methylbenzene & 9 & 0.287252782 & & \\
\hline & 1,3,5-trimethylbenzene & 9 & 0.383337337 & & \\
\hline & 2-ethyl-1-methylbenzene & 9 & 0.462406918 & & \\
\hline & 1,2,4-trimethylbenzene & 9 & 1.304147650 & & \\
\hline & 1,2,3-trimethylbenzene & 9 & 0.244214909 & & \\
\hline & sec-butylbenzene & 10 & 0.012010569 & \multirow{13}{*}{ averaged } & \multirow{13}{*}{0.440387541} \\
\hline & 3-isopropyl-1-methylbenzene & 10 & 0.033029066 & & \\
\hline & 4-isopropyl-1-methylbenzene & 10 & 0.009007927 & & \\
\hline & 1,3-diethylbenzene & 10 & 0.030026423 & & \\
\hline & 3-propyl-1-methylbenzene & 10 & 0.080070462 & & \\
\hline & 4-propyl-1-methylbenzene & 10 & 0.035030827 & & \\
\hline & n-butylbenzene & 10 & 0.016014092 & & \\
\hline & 5-ethyl-1,3-dimethylbenzene & 10 & 0.059051966 & & \\
\hline & 2-propyl-1-methylbenzene & 10 & 0.021018496 & & \\
\hline & 2-ethyl-1,4-dimethylbenzene & 10 & 0.038033469 & & \\
\hline & 4-ethyl-1,3-dimethylbenzene & 10 & 0.033029066 & & \\
\hline & 4-ethyl-1,2-dimethylbenzene & 10 & 0.059051966 & & \\
\hline & 3-ethyl-1,2-dimethylbenzene & 10 & 0.015013212 & & \\
\hline & 4-isoproyl-1-ethylbenzene & 11 & 0.023020258 & \multirow{2}{*}{ averaged } & \multirow{2}{*}{0.055048443} \\
\hline & 1-butyl-1-methylbenzene & 11 & 0.032028185 & & \\
\hline \multirow{4}{*}{ 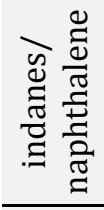 } & 5-methylindan & 10 & 0.010008808 & \multirow{4}{*}{ indane $\left(\mathrm{C}_{9} \mathrm{H}_{10}\right)$} & \multirow{4}{*}{0.104091601} \\
\hline & 2-methylindan & 10 & 0.009007927 & & \\
\hline & naphthalene & 10 & 0.019016735 & & \\
\hline & indane (indenes) & 9 & 0.066058131 & & \\
\hline \multirow{5}{*}{ 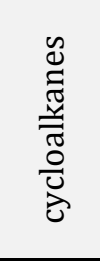 } & 3c-ethylmethylcyclopentane & 8 & 1.345183762 & \multirow{5}{*}{$\begin{array}{l}\text { 3c-ethylmethylcyclopentane } \\
\qquad\left(\mathrm{C}_{8} \mathrm{H}_{16}\right)\end{array}$} & \multirow{5}{*}{1.491312355} \\
\hline & 1,1,methylethylcyclopentane & 8 & 0.022019377 & & \\
\hline & c8 - mononaph - 3 & 8 & 0.060052847 & & \\
\hline & methylcycloheptane & 8 & 0.046040516 & & \\
\hline & 1-methyl-2-propylcyclohexane & 10 & 0.018015854 & & \\
\hline \multirow{7}{*}{$\begin{array}{l}\sum_{0}^{0} \\
\frac{0}{0}\end{array}$} & 1-pentene & 5 & 0.046040516 & \multirow{7}{*}{ 1-nonene $\left(\mathrm{C}_{9} \mathrm{H}_{18}\right)$} & \multirow{7}{*}{0.346304748} \\
\hline & c-pentene- 2 & 5 & 0.016014092 & & \\
\hline & 1-hexene & 6 & 0.007006165 & & \\
\hline & 1-nonene & 9 & 0.195171751 & & \\
\hline & (z) 2-decene & 10 & 0.056049323 & & \\
\hline & 3-ethyl-2-methyl-2-heptene & 10 & 0.013011450 & & \\
\hline & c-10-isoolefin-9 & 10 & 0.013011450 & & \\
\hline
\end{tabular}


Table 2

\begin{tabular}{lrcc}
\hline$m$ & \multicolumn{1}{c}{ group } & $\begin{array}{c}\text { molar } \\
\text { fractions (\%) }\end{array}$ & $\begin{array}{c}\text { number of } \\
\text { components }\end{array}$ \\
\hline 1 & n-alkanes & 28.50 & 5 \\
2 & iso-alkanes & 65.18 & 8 \\
3 & aromatics & 4.40 & 4 \\
4 & indanes/naphthalenes & 0.10 & 1 \\
5 & cycloalkanes & 0.33 & 1 \\
6 & olefins & 1.49 & 1 \\
\hline
\end{tabular}

Table 3

\begin{tabular}{rccccccc}
\hline total number of QC/C & 15 & 11 & 7 & 6 & 5 & 4 & 3 \\
groups & & & & & & & \\
\hline iso-alkanes & 3 & 2 & 2 & 2 & 2 & 1 & 1 \\
aromatics & 3 & 2 & 2 & 2 & 2 & 2 & 1 \\
indanes/naphthalenes & 1 & 1 & 0 & 0 & 0 & 0 & 0 \\
cycloalkanes & 1 & 1 & 0 & 0 & 0 & 0 & 0 \\
olefins & 1 & 1 & 0 & 0 & 0 & 0 & 0 \\
\hline
\end{tabular}

Table 4

\begin{tabular}{rccccc}
\hline component & $n$ & $A$ & $B$ & $C$ & $D$ \\
\hline n-butane & 4 & -4.6402 & $4.850 \mathrm{E} 2$ & $1.340 \mathrm{E}-2$ & $-1.970 \mathrm{E}-5$ \\
n-pentane & 5 & -7.1711 & $7.470 \mathrm{E} 2$ & $2.170 \mathrm{E}-2$ & $-2.720 \mathrm{E}-5$ \\
n-hexane & 6 & -5.0715 & $6.550 \mathrm{E} 2$ & $1.230 \mathrm{E}-2$ & $-1.50 \mathrm{E}-5$ \\
n-decane & 10 & -6.0716 & $1.020 \mathrm{E} 3$ & $1.220 \mathrm{E}-2$ & $-1.190 \mathrm{E}-5$ \\
n-dodecane & 12 & -7.0687 & $1.263 \mathrm{E} 3$ & $1.3735 \mathrm{E}-2$ & $-1.2215 \mathrm{E}-5$ \\
\hline
\end{tabular}


Table 5

\begin{tabular}{|c|c|c|}
\hline group & carbon number & $\begin{array}{l}\text { relative density } \\
(\tilde{\rho})\end{array}$ \\
\hline \multirow{5}{*}{ 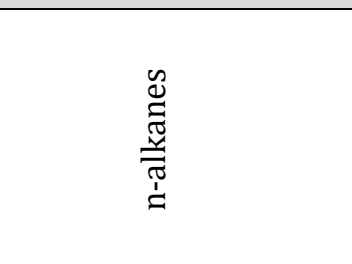 } & 4 & 0.592 \\
\hline & 5 & 0.631 \\
\hline & 6 & 0.662 \\
\hline & 10 & 0.737 \\
\hline & 12 & 0.753 \\
\hline \multirow{8}{*}{ 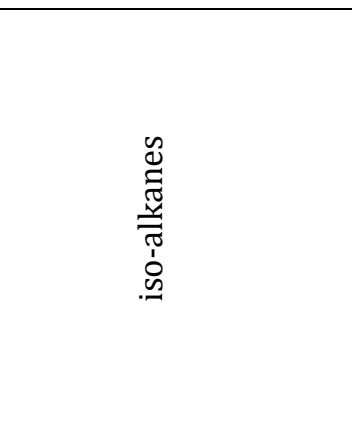 } & 4 & 0.566 \\
\hline & 5 & 0.620 \\
\hline & 6 & 0.661 \\
\hline & 7 & 0.691 \\
\hline & 8 & 0.713 \\
\hline & 9 & 0.729 \\
\hline & 10 & 0.739 \\
\hline & 11 & 0.743 \\
\hline \multirow{4}{*}{ 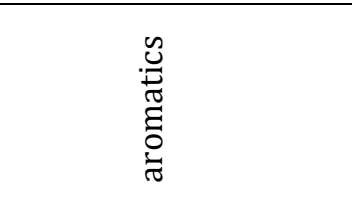 } & 8 & 0.884 \\
\hline & 9 & 0.875 \\
\hline & 10 & 0.872 \\
\hline & 11 & 0.862 \\
\hline indanes/naphthalenes & 9 & 0.969 \\
\hline cycloalkanes & 8 & 0.771 \\
\hline olefins & 9 & 0.733 \\
\hline
\end{tabular}

Table 6

\begin{tabular}{rcccc}
\hline group & $A^{*}$ & $a$ & $\beta$ & $\gamma$ \\
\hline n-/iso- alkanes & 0.0035 & 1.2 & 0.5 & 0.167 \\
aromatics & 0.0346 & 1.2 & 1 & 0.167 \\
indanes/naphthalenes & 0.035 & 1.2 & 0.5 & 0.167 \\
cycloalkanes & 0.031 & 1.2 & 1 & 0.167 \\
olefins & 0.0361 & 1.2 & 1 & 0.167 \\
\hline
\end{tabular}

Table 7

\begin{tabular}{cccccc}
\hline component & $n$ & $A$ & $B$ & $T$ & $T_{c}$ \\
\hline n-butane & 4 & 33.0198 & 0.377 & 272.65 & 425.13 \\
n-pentane & 5 & 39.8543 & 0.398 & 309.22 & 469.65 \\
n-hexane & 6 & 45.610 & 0.401 & 341.88 & 507.43 \\
n-decane & 10 & 71.4282 & 0.451 & 447.30 & 618.45 \\
n-dodecane & 12 & 77.1658 & 0.407 & 489.47 & 658.20 \\
\hline
\end{tabular}


Table 8

\begin{tabular}{cccccc}
\hline component & $n$ & $A$ & $B$ & $C$ & $D$ \\
\hline i-butane & 4 & -1.80770 & 258.930 & 0.003021 & $-8.64410 \mathrm{E}-06$ \\
$\mathrm{C}_{5} \mathrm{H}_{12}$ & 5 & -5.80889 & 706.6875 & 0.014813 & $-1.85303 \mathrm{E}-05$ \\
$\mathrm{C}_{6} \mathrm{H}_{14}$ & 6 & -10.2364 & 1387.157 & 0.024213 & $-2.40762 \mathrm{E}-05$ \\
$\mathrm{C}_{7} \mathrm{H}_{16}$ & 7 & -4.84309 & 641.4304 & 0.011545 & $-1.37435 \mathrm{E}-05$ \\
$\mathrm{C}_{8} \mathrm{H}_{18}$ & 8 & -10.2217 & 1423.586 & 0.024242 & $-2.33636 \mathrm{E}-05$ \\
$\mathrm{C}_{9} \mathrm{H}_{20}$ & 9 & -4.25773 & 652.8668 & 0.008355 & $-8.98181 \mathrm{E}-06$ \\
$\mathrm{C}_{10} \mathrm{H}_{22}$ & 10 & -4.8378 & 782.6433 & 0.009299 & $-9.37893 \mathrm{E}-06$ \\
$\mathrm{C}_{11} \mathrm{H}_{24}$ & 11 & -4.23052 & 709.6763 & 0.007402 & $-7.41622 \mathrm{E}-06$ \\
\hline
\end{tabular}

Table 9

\begin{tabular}{cccc}
\hline component & $n$ & $A$ & $B$ \\
\hline i-butane & 4 & 31.95380 & 0.392 \\
$\mathrm{C}_{5} \mathrm{H}_{12}$ & 5 & 37.68615 & 0.394981 \\
$\mathrm{C}_{6} \mathrm{H}_{14}$ & 6 & 42.32119 & 0.389105 \\
$\mathrm{C}_{7} \mathrm{H}_{16}$ & 7 & 46.95571 & 0.388222 \\
$\mathrm{C}_{8} \mathrm{H}_{18}$ & 8 & 49.32456 & 0.382229 \\
$\mathrm{C}_{9} \mathrm{H}_{20}$ & 9 & 56.10624 & 0.38 \\
$\mathrm{C}_{10} \mathrm{H}_{22}$ & 10 & 59.25229 & 0.38 \\
$\mathrm{C}_{11} \mathrm{H}_{24}$ & 11 & 65.11180 & 0.38 \\
\hline
\end{tabular}

Table 10

\begin{tabular}{ccccc}
\hline component & $n$ & $A$ & $B$ & $C$ \\
\hline o-xylene & 8 & 0.28760 & 0.265130 & 0.27410 \\
$\mathrm{C}_{9} \mathrm{H}_{12}$ & 9 & 0.269256 & 0.249881 & 0.274542 \\
$\mathrm{C}_{10} \mathrm{H}_{14}$ & 10 & 0.276930 & 0.258413 & 0.288381 \\
$\mathrm{C}_{11} \mathrm{H}_{16}$ & 11 & 0.275810 & 0.262610 & 0.285710 \\
\hline
\end{tabular}

Table 11

\begin{tabular}{cccccc}
\hline component & $n$ & $A$ & $B$ & $C$ & $D$ \\
\hline o-xylene & 8 & -7.8805 & 1250.0 & 0.016116 & $-1.39930 \mathrm{E}-05$ \\
$\mathrm{C}_{9} \mathrm{H}_{12}$ & 9 & -5.30135209 & 897.6554 & 0.009761 & $-8.86622 \mathrm{E}-06$ \\
$\mathrm{C}_{10} \mathrm{H}_{14}$ & 10 & -4.346850 & 781.4415 & 0.007281 & $-6.73705 \mathrm{E}-06$ \\
$\mathrm{C}_{11} \mathrm{H}_{16}$ & 11 & -4.6410 & 853.230 & 0.007850 & $-7.10120 \mathrm{E}-06$ \\
\hline
\end{tabular}

Table 12

\begin{tabular}{cccc}
\hline Component & $n$ & $A$ & $B$ \\
\hline o-xylene & 8 & 55.6060 & 0.3750 \\
$\mathrm{C}_{9} \mathrm{H}_{12}$ & 9 & 59.97485694 & 0.38526 \\
$\mathrm{C}_{10} \mathrm{H}_{14}$ & 10 & 63.32651773 & 0.379614 \\
$\mathrm{C}_{11} \mathrm{H}_{16}$ & 11 & 65.20160 & 0.380 \\
\hline
\end{tabular}


Table 13

\begin{tabular}{rccc}
\hline \multicolumn{1}{c}{ group } & $A$ & $B$ & $C$ \\
\hline indanes/naphthalenes & 310.20 & 0.26114 & 0.30223 \\
cycloalkanes & 264.97 & 0.27385 & 0.28571 \\
olefins & 239.10 & 0.25815 & 0.28571 \\
\hline
\end{tabular}

Table 14

\begin{tabular}{rcccc}
\hline \multicolumn{1}{c}{ group } & $A$ & $B$ & $C$ & $D$ \\
\hline indanes/naphthalenes & -7.3304 & 1330.6 & 0.0126170 & $-8.6008 \mathrm{E}-6$ \\
cycloalkanes & -4.2467 & 654.41 & 0.0085394 & $-9.3374 \mathrm{E}-6$ \\
olefins & -6.5557 & 993.50 & 0.0142320 & $-1.4097 \mathrm{E}-5$ \\
\hline
\end{tabular}

Table 15

\begin{tabular}{rcc}
\hline \multicolumn{1}{c}{ group } & $A$ & $B$ \\
\hline indanes/naphthalenes & 62.1067 & 0.42 \\
cycloalkanes & 50.9505 & 0.38 \\
olefins & 61.7073 & 0.38 \\
\hline
\end{tabular}

